\title{
Estimates of aerosol radiative forcing from the MACC re-analysis
}

\author{
N. Bellouin ${ }^{1, *}$, J. Quaas ${ }^{2}$, J.-J. Morcrette ${ }^{3}$, and O. Boucher ${ }^{4}$ \\ ${ }^{1}$ Met Office Hadley Centre, Exeter, UK \\ ${ }^{2}$ Universität Leipzig, Leipzig, Germany \\ ${ }^{3}$ European Centre for Medium-range Weather Forecast, Reading, UK \\ ${ }^{4}$ Laboratoire de Météorologie Dynamique, IPSL, CNRS/UPMC, Paris, France \\ *now at: Department of Meteorology, University of Reading, Reading, UK
}

Correspondence to: N. Bellouin (n.bellouin@ reading.ac.uk)

Received: 26 July 2012 - Published in Atmos. Chem. Phys. Discuss.: 10 August 2012

Revised: 13 February 2013 - Accepted: 16 February 2013 - Published: 21 February 2013

\begin{abstract}
The European Centre for Medium-range Weather Forecast (ECMWF) provides an aerosol re-analysis starting from year 2003 for the Monitoring Atmospheric Composition and Climate (MACC) project. The re-analysis assimilates total aerosol optical depth retrieved by the Moderate Resolution Imaging Spectroradiometer (MODIS) to correct for model departures from observed aerosols. The reanalysis therefore combines satellite retrievals with the full spatial coverage of a numerical model. Re-analysed products are used here to estimate the shortwave direct and first indirect radiative forcing of anthropogenic aerosols over the period 2003-2010, using methods previously applied to satellite retrievals of aerosols and clouds. The best estimate of globally-averaged, all-sky direct radiative forcing is $-0.7 \pm 0.3 \mathrm{Wm}^{-2}$. The standard deviation is obtained by a Monte-Carlo analysis of uncertainties, which accounts for uncertainties in the aerosol anthropogenic fraction, aerosol absorption, and cloudy-sky effects. Further accounting for differences between the present-day natural and pre-industrial aerosols provides a direct radiative forcing estimate of $-0.4 \pm 0.3 \mathrm{Wm}^{-2}$. The best estimate of globally-averaged, all-sky first indirect radiative forcing is $-0.6 \pm 0.4 \mathrm{Wm}^{-2}$. Its standard deviation accounts for uncertainties in the aerosol anthropogenic fraction, and in cloud albedo and cloud droplet number concentration susceptibilities to aerosol changes. The distribution of first indirect radiative forcing is asymmetric and is bounded by -0.1 and $-2.0 \mathrm{Wm}^{-2}$. In order to decrease uncertainty ranges, better observational constraints on aerosol absorption and sensitivity of cloud droplet number concentrations to aerosol changes are required.
\end{abstract}

\section{Introduction}

The main interactions between natural and anthropogenic aerosols and the climate system are through scattering and absorption of radiation (direct radiative effect, DRE), and modification of the microphysical properties of clouds, impacting cloud albedo (first indirect effect), cloud evolution and precipitation efficiency (second indirect effect). Anthropogenic aerosols, emitted into the atmosphere by human activities, are considered external to the climate system, and their marginal contributions to the direct and indirect effects are termed forcing (Forster et al., 2007).

Direct and first indirect radiative forcing, hereafter abbreviated as DRF and IRF, respectively, have been estimated using aerosol numerical modelling or satellite retrievals. Numerical models simulate the complexity of real aerosol distributions, but make simplifying assumptions in doing so. They represent emissions, chemistry, transport, and sinks of aerosols to simulate the three-dimensional distributions of particle mass and number for several aerosol species. Those distributions are then provided to the radiation scheme where aerosol direct effects are included in the calculation of radiative fluxes. Cloud droplet number concentrations (CDNC) can also be computed from the aerosol distributions and used in the calculation of cloud optical properties, thus representing the first indirect effect. Representation of the second indirect effect in large-scale climate models has been attempted by parameterising precipitation formation as simple functions of the CDNC, although the value of this method is debated (Stevens and Feingold, 2009), with evidence of climate models overpredicting the strength of the second 
indirect effect (Quaas et al., 2009; Wang et al., 2012). Since second indirect effects involve adjustments of cloud distributions that are not explicitly represented in the datasets used, this study focuses on the first aerosol indirect effect only. Aerosol DRF and IRF are typically computed from two parallel model simulations, the first using present-day aerosol emissions, the second using pre-industrial aerosol emissions, and both sharing the same meteorology so that changes in radiative flux are only due to anthropogenic changes in aerosols.

From a purely observational point of view, the task of estimating DRF and IRF involves distributions of total aerosol and cloud retrieved from satellite instruments. Since the preindustrial state has not been observed, the determination of the anthropogenic aerosol fraction is difficult and involves proxies for the aerosol origin, such as the size of the aerosol particles. Satellite instruments also do not offer full coverage of the Earth's aerosol distribution, as aerosol optical depths (AODs) are not yet routinely retrieved in cloudy sky and are less accurate over bright surfaces. This introduces sampling biases in the spatial and temporal statistics.

The AeroCom intercomparison project of aerosol modelling reported a DRF with respect to pre-industrial conditions, represented by the year 1750 , of $-0.2 \pm 0.2 \mathrm{Wm}^{-2}$ (Schulz et al., 2006). The latest assessment report of the Intergovernmental Panel on Climate Change (IPCC) (Forster et al., 2007) added the more uncertain impact of anthropogenic nitrate and mineral dust aerosols to reach a best estimate of the DRF of $-0.4 \pm 0.4 \mathrm{Wm}^{-2}$. On the observational side and for total aerosol, a review of measurement-based studies of the DRE by Yu et al. (2006) concluded that the best estimates of top-of-atmosphere (TOA) DRE are $-5.5 \pm 0.2$ and $-4.9 \pm 0.7 \mathrm{Wm}^{-2}$ over cloud-free ocean and land surfaces, respectively. For anthropogenic aerosols, Kaufman et al. (2005a) estimated a DRF of $-1.4 \pm 0.4 \mathrm{Wm}^{-2}$ over cloud-free oceans by using MODIS (Moderate Resolution Imaging Spectroradiometer) retrievals of total AOD and its fine-mode fraction (FMF), combined with DRF efficiencies, defined as DRF per unit AOD. Christopher et al. (2006) provided the same estimate using a different method also limited to cloud-free oceans: they combined MODIS total AODs and CERES (Clouds and the Earth's Radiant Energy System) broadband radiative fluxes. Yu et al. (2004) and Chung et al. (2005) combined model simulations and satellite observations to estimate a DRF of -1.4 and $-1.1 \mathrm{Wm}^{-2}$, respectively, in cloud-free conditions. Chung et al. (2005) also provided an all-sky estimate ranging from -0.6 to $-0.1 \mathrm{Wm}^{-2}$ by using monthly distributions of satellite cloud retrievals with prescribed aerosol vertical profiles. Bellouin et al. (2005, 2008) used MODIS retrievals of total AOD combined with its FMF over oceans and model-derived anthropogenic fractions over land surfaces. Their more recent estimate of the DRF, based on MODIS collection 5 data, is $-1.3 \mathrm{Wm}^{-2}$ globally in cloud-free conditions. Assuming no aerosol DRF in cloudy sky, they scaled the cloud-free value to obtain $-0.7 \mathrm{Wm}^{-2}$ in all-sky conditions. As noted by Forster et al. (2007), satellite-based estimates of the DRF are therefore typically stronger than those by numerical models. Bellouin et al. (2008) suggested that those differences are due to the incomplete sampling of the total aerosol distribution by satellite instruments and to differences in pre-industrial and present-day natural aerosol distributions, which are used as references for the DRF in numerical models and satellitebased estimates, respectively. Myhre (2009) also attributed some of the discrepancy to changes in aerosol absorption between pre-industrial and present times, which can be accounted for in model estimates but not in satellite-derived estimates.

For the IRF, Forster et al. (2007) acknowledged that the spread in model results is larger than for the DRF and give, for liquid clouds, a median estimate of $-0.7 \mathrm{Wm}^{-2}$, with a $5-95 \%$ confidence interval range of -0.3 to $-1.8 \mathrm{Wm}^{-2}$. On the observational side, Quaas et al. (2008) used a combination of CERES and MODIS retrievals to estimate the IRF at only $-0.2 \pm 0.1 \mathrm{Wm}^{-2}$. Furthermore, Quaas et al. (2009) found that constraining numerical models with satellite observations decreases the IRF estimate from models.

In contrast to satellite retrievals, numerical aerosol models simulate the full spatial and temporal distributions of aerosols, without data gaps. Sampling can have a large impact on DRF estimates. For example, Bellouin et al. (2008) showed that sampling the DRF obtained from a general circulation model according to the aerosol retrieval mask of MODIS was enough to increase the globally-averaged DRF by $12 \%$. However, relying purely on models is a poor solution because modelling the atmospheric aerosol life cycle from emission to deposition is challenging and modelled distributions can differ markedly from observations. Assimilating satellite retrievals of aerosols into a numerical model can therefore be a useful compromise, providing full coverage while keeping a strong tie with observed aerosols. Morcrette et al. (2009) and Benedetti et al. (2009) have developed an aerosol data assimilation system within the European Centre for Medium-range Weather Forecast (ECMWF) Integrated Forecast System (IFS). Within the European Framework Programme 7 MACC (Monitoring Atmospheric Composition and Climate) and MACC-II projects, this system provides aerosol forecasts, a re-analysis which covers 2003 to 2010, and an ongoing analysis.

In this paper, the re-analysed aerosol distributions are used to estimate the DRF and IRF. Section 2 describes the MACC aerosol re-analysis. Section 3 then describes the process whereby total AOD is distributed among four aerosol types, including the anthropogenic fraction. Sections 4 and 5 describe how the component AODs can be used to estimate the DRE, DRF, and IRF, with results covering the reanalysed period 2003-2010. Section 7 describes the MonteCarlo analysis of uncertainties. The paper concludes by discussing the strengths and weaknesses of the MACC forcing estimates, as well as listing their possible uses. 


\section{The MACC aerosol re-analysis}

The aerosol analysis and forecast system of the ECMWF IFS consists of a forward model (Morcrette et al., 2009) and a data-assimilation module (Benedetti et al., 2009). The forward model simulates the mass of five aerosol species: mineral dust, sea salt, sulphate, black carbon (BC), and organic matter $(\mathrm{OM})$. Mineral dust and sea salt are represented by three different size classes each, and hydrophilic and hydrophobic modes of $\mathrm{BC}$ and $\mathrm{OM}$ are distinguished. This sums up to 11 model tracers. Emissions of mineral dust and sea salt depend on modelled near-surface wind speeds. For the other species, emissions are provided by inventories of sulphur dioxide and primary BC and OM. BC and OM experience ageing from hydrophobic to hydrophilic components with a time constant of 1.16 days. Sulphur dioxide oxidation into sulphate aerosol is represented by a prescribed, latitudedependent e-folding time scale ranging from 3 days at the Equator to 8 days at the poles. Sinks include dry deposition, sedimentation, and wet scavenging by large-scale and convective precipitation. The model diagnoses total and component AODs at 17 wavelengths from 0.34 to $2.13 \mu \mathrm{m}$ by using the optical properties listed in Sect. 4.2 of Morcrette et al. (2009) and assuming that aerosols are externally mixed. Morcrette et al. (2009) showed that this simple aerosol model compares reasonably well with observations.

The agreement with observations improves when the aerosol data assimilation system is used, as described and validated by Benedetti et al. (2009) and Mangold et al. (2011). Data assimilation consists in the minimisation of a complicated cost-function and updates the modelled aerosol masses in order to match observations more closely. This has been done by using the ECMWF four-dimensional variational assimilation method, which accounts for background and observational errors. The assimilated observation is the total AOD at $0.55 \mu \mathrm{m}$ from MODIS, available in cloud-free conditions over dark surfaces. The model control variable, which is modified according to the outcome of the data assimilation, is the total aerosol mass-mixing ratio. It is worth noting that the assimilation modifies the modelled field not only at the point of the observation but also around it. Regions with no observations because of cloudiness or high surface reflectance will still be improved by data assimilation, but to a lesser extent than regions close to the location of assimilated data. During data assimilation, each aerosol component is corrected in proportion of its original contribution to the total aerosol mass. This mass increment is then converted to an AOD and compared against the assimilated MODIS retrieval, until convergence is achieved within observational and model errors. The modelled speciation therefore remains untouched because the assimilated total AOD can only provide a single constraint: assimilation of additional observations, such as the satellite-derived FMF, is needed to also affect the modelled speciation. Nevertheless, assimila- tion corrects total AOD for aerosol species that are not represented in the forward model, such as nitrate.

Data assimilation can be used to initialise a forecast when done in near-real time but an analysis can also be done in retrospect using a stable version of the model. The analysis is of interest to the estimate of aerosol forcing and is used here. The top row of Fig. 2 shows the 2003-2010 seasonal averages of total AOD at $0.55 \mu \mathrm{m}$ as provided by the MACC re-analysis with data assimilation. The annual and global average AOD of 0.180 is similar to that obtained from satellite retrievals, but is larger than free-running numerical simulations, with the median total AOD in AeroCom models being 0.127 (Kinne et al., 2006).

The guiding principle of the derivation of aerosol forcing from the aerosol distributions of the MACC re-analysis is to rely first on variables that are affected by data assimilation and combine them with observational estimates of other variables, such as aerosol optical properties or cloud susceptibility to aerosol changes. Unfortunately, it is not possible to completely avoid using modelled fields that are not affected by the data assimilation. For example, although the aerosol forcing estimation does not rely on aerosol speciation, it does use an associated variable, the FMF of the total AOD. In this study, fine-mode particles are those with radii smaller than $0.5 \mu \mathrm{m}$, in agreement with the definition used for the MODIS retrieval of the FMF.

\section{Identification of aerosol origin}

The IFS does not provide the anthropogenic fraction of the simulated aerosols for three reasons. Firstly, the aerosol origin is not always given in emission inventories, with some sectors, such as biomass-burning activities, being the sum of both natural and anthropogenic sources. Secondly, even if emissions could be broken down by aerosol origins, the model would require double the number of tracers to keep track of that information within the simulation. That would be costly and complex when natural and anthropogenic particles interact with each other. Lastly, data assimilation is based on the total aerosol column and cannot constrain natural and anthropogenic aerosols independently.

Arguably, one could simply classify mineral dust and seasalt as natural aerosols, and sulphate, black carbon, and organic carbon as anthropogenic aerosols. Unfortunately, this simple method gives poor results, since a significant fraction of sulphate is produced from oxidation of naturallyoccurring dimethyl sulphide over the oceans, and because vegetation and other natural sources produce secondary organic aerosols over land. Instead, the aerosol origin is obtained using a modified version of the algorithm by Bellouin et al. (2008) where aerosol size is used as a proxy for aerosol origin. The algorithm used over ocean surfaces is summarised by the flowchart shown in Fig. 1 . 
Table 1. Parameters used to derive the anthropogenic aerosol optical depth over land and to prescribe aerosol optical properties over ocean and land surfaces for the four aerosol components. The single-scattering albedo is given at $0.55 \mu \mathrm{m}$. Optical properties for the anthropogenic aerosol component are prescribed regionally. Representative AERONET sites refer to the sites studied by Dubovik et al. (2002). For the other components, optical properties are prescribed globally. Standard deviations are used in the Monte-Carlo uncertainty analysis described in Sect. 7 .

\begin{tabular}{|c|c|c|c|c|c|}
\hline Aerosol type & \multicolumn{2}{|c|}{ Regional boundaries } & $\begin{array}{l}\text { Anthropogenic fraction } \\
\text { over land }\end{array}$ & $\begin{array}{l}\text { Representative } \\
\text { AERONET site }\end{array}$ & $\begin{array}{l}\text { Single-scattering } \\
\text { albedo }\end{array}$ \\
\hline Mineral dust & \multicolumn{2}{|c|}{ Global } & & Cape Verde & 0.98 \\
\hline Marine & \multicolumn{2}{|c|}{ Global } & & Hawaii & 0.99 \\
\hline Fine-mode natural & \multicolumn{2}{|c|}{ Global } & & & 0.98 \\
\hline \multicolumn{6}{|l|}{ Anthropogenic } \\
\hline North America & $90^{\circ} \mathrm{N}-30^{\circ} \mathrm{N}$ & $180^{\circ} \mathrm{W}-30^{\circ} \mathrm{W}$ & $0.69 \pm 0.20$ & GSFC (USA) & $0.98 \pm 0.03$ \\
\hline Eurasia & $90^{\circ} \mathrm{N}-30^{\circ} \mathrm{N}$ & $30^{\circ} \mathrm{W}-180^{\circ} \mathrm{E}$ & $0.77 \pm 0.20$ & Créteil (France) & $0.94 \pm 0.03$ \\
\hline Central America & $30^{\circ} \mathrm{N}-0$ & $120^{\circ} \mathrm{W}-60^{\circ} \mathrm{W}$ & $0.63 \pm 0.20$ & Mexico City (Mexico) & $0.90 \pm 0.03$ \\
\hline South America & $30^{\circ} \mathrm{N}-90^{\circ} \mathrm{S}$ & $180^{\circ} \mathrm{W}-30^{\circ} \mathrm{W}$ & $0.69 \pm 0.20$ & Brazil & $0.91 \pm 0.03$ \\
\hline Africa and Oceania & $30^{\circ} \mathrm{N}-90^{\circ} \mathrm{S}$ & $30^{\circ} \mathrm{W}-180^{\circ} \mathrm{E}$ & $0.77 \pm 0.20$ & Mongu (Zambia) & $0.86 \pm 0.03$ \\
\hline India & $30^{\circ} \mathrm{E}-120^{\circ} \mathrm{E}$ & $30^{\circ} \mathrm{N}-10^{\circ} \mathrm{S}$ & $0.82 \pm 0.20$ & Maldives & $0.91 \pm 0.03$ \\
\hline
\end{tabular}

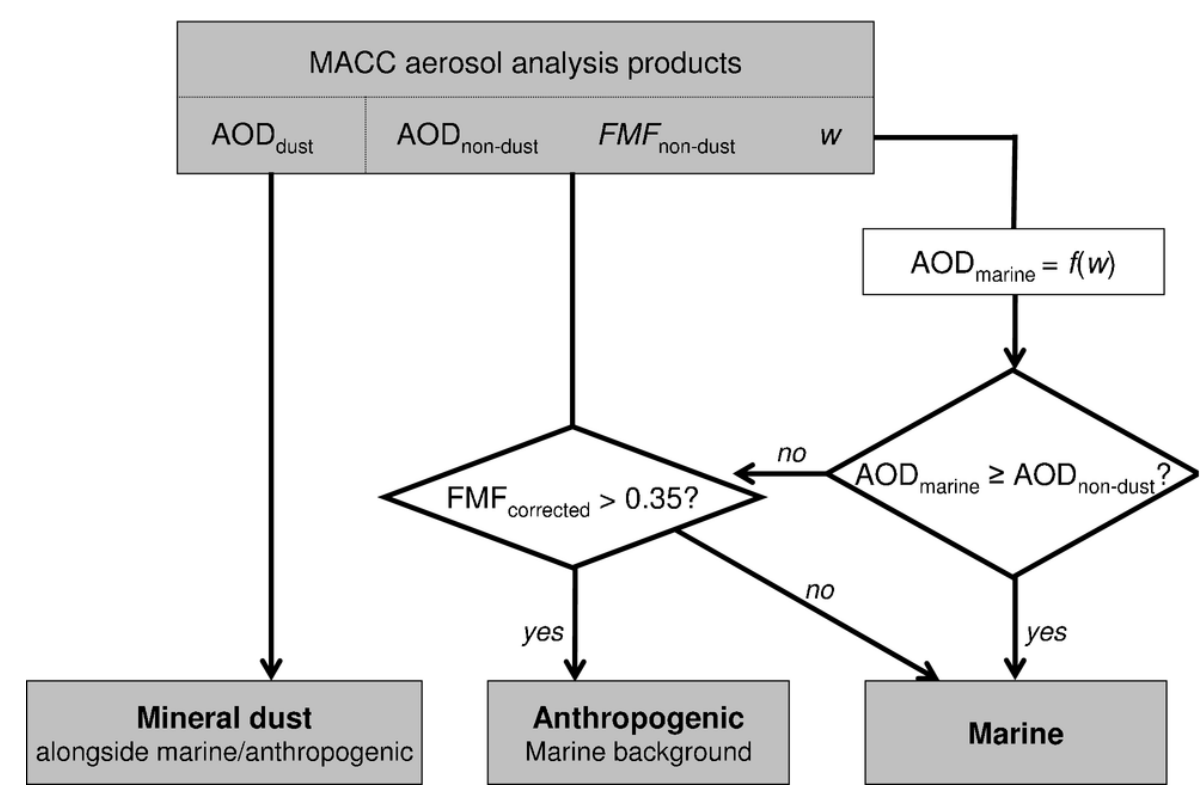

Fig. 1. Flow diagram of the algorithm used to identify mineral dust, anthropogenic, and marine aerosols from the MACC reanalysis of the aerosol optical depth (AOD) and fine-mode fraction (FMF) over the ocean. $w$ is the near-surface windspeed simulated by the model. $\mathrm{FMF}_{\text {corrected }}$ is the FMF corrected for the contribution of marine aerosols.

The algorithm starts with the identification of the mineral dust component. The original algorithm of Bellouin et al. (2008) assumes that mineral dust aerosols are large, UVabsorbing particles with FMF smaller than 0.35. Although this assumption is based on in-situ measurements of aerosol properties, it is not verified in the version of the IFS used for the MACC re-analysis. Due to assumptions made on the size of emitted mineral dust particles, a large fraction of mineral dust is located in the fine mode in the MACC aerosol reanalysis. Consequently, in this instance there is no other choice than to trust the modelled speciation and use the mineral dust AOD as simulated, without further processing.
The non-dust AOD, noted $\tau_{\text {non-dust }}$, must now be distributed to the other components. Over ocean, these components can be marine and anthropogenic aerosols. The marine aerosol component encompasses sea salt and fine-mode natural aerosols produced at the atmosphere-ocean interface, such as sulphate from dimethyl sulphide oxidation, and organics. Fine-mode natural aerosols advected from the continents are also likely to contribute to the non-dust AOD, but are not identified independently. The identification starts with a first guess of the marine optical depth, computed from the $10 \mathrm{~m}$ 


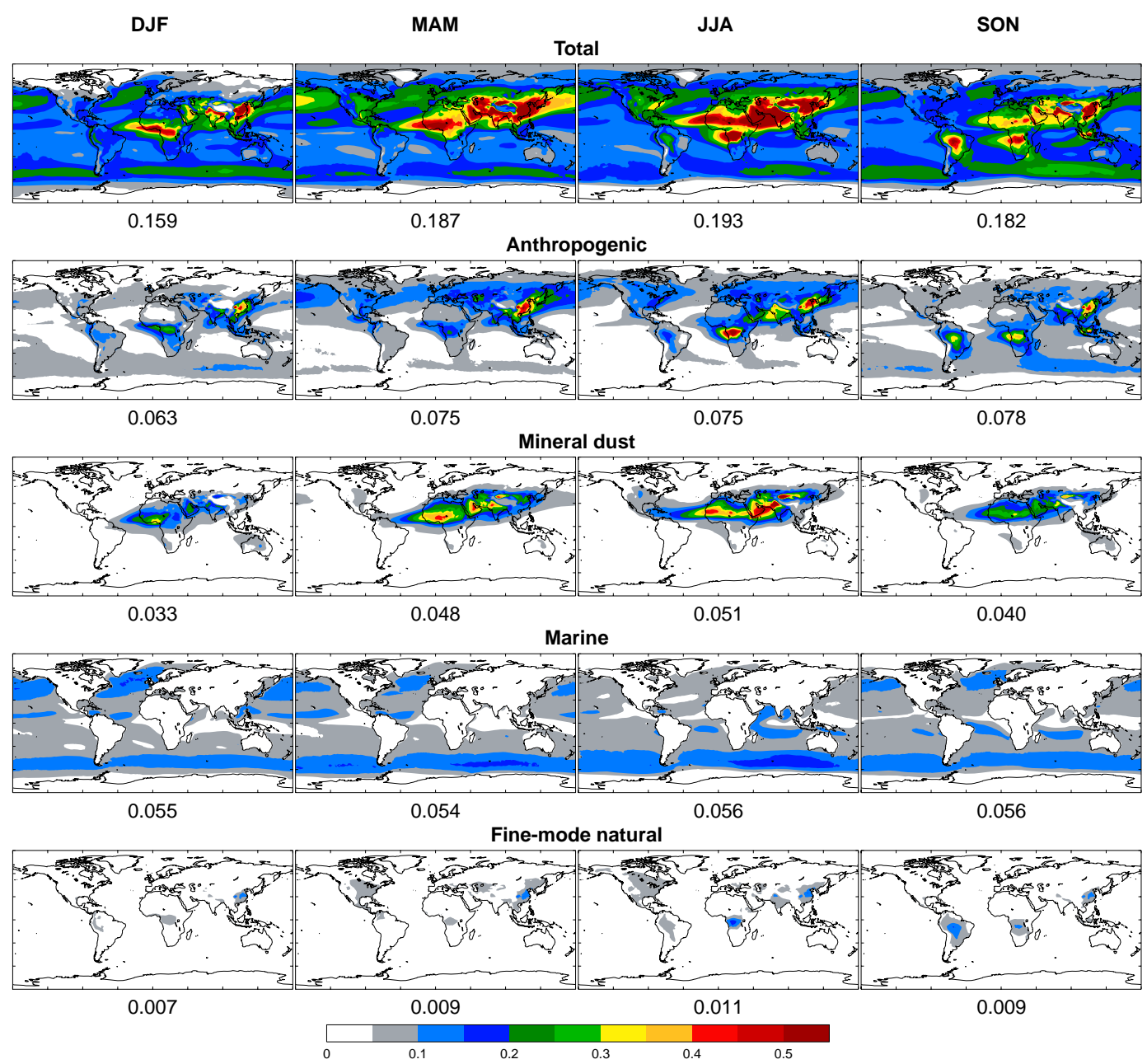

Fig. 2. Seasonal distributions of aerosol optical depth at $0.55 \mu \mathrm{m}$ as derived from the MACC re-analysis over 2003-2010. From top to bottom, the optical depth is for total, anthropogenic, mineral dust, marine, and fine-mode natural aerosols. Global averages are given by the numbers below each panel.

wind speed, $w$, as suggested by Smirnov et al. (2003):

$$
\begin{aligned}
\tau_{\text {marine }} & =0.006 w+0.06 \text { if } w>5 \mathrm{~m} \mathrm{~s}^{-1} \\
& =0 \text { if } w<5 \mathrm{~ms}^{-1}
\end{aligned}
$$

where $w$ is taken from the IFS re-analysis. If the first guess is larger or equal to $\tau_{\text {non-dust }}$, then marine aerosol is the only component identified in the grid-box and its AOD is $\tau_{\text {non-dust }}$. Otherwise, the non-dust FMF needs to be corrected for the contribution of marine aerosol before going further. The non-dust FMF, noted $f_{\text {non-dust }}$, is computed as:

$f_{\text {non-dust }}=$

$\tau_{\text {sulphate }}+\tau_{\text {black-carbon }}+\tau_{\text {organic-matter }}+\tau_{\text {seasalt }} \cdot f_{\text {seasalt }}$

$\tau_{\text {sulphate }}+\tau_{\text {black-carbon }}+\tau_{\text {organic-matter }}+\tau_{\text {seasalt }}$

where $f_{\text {seasalt }}$ is the FMF of sea salt aerosols, assumed to be 0.3. This calculation is consistent with the size distributions assumed in the IFS, where sulphate, organic matter, and black carbon aerosols are fully in the fine-mode, and $30 \%$ of globally-averaged sea-salt AOD is due to the two bins below $0.5 \mu \mathrm{m}$. Then, the FMF corrected for the marine contribution is computed as:

$$
f_{\text {corrected }}=\frac{f_{\text {non-dust }} \tau_{\text {non-dust }}-f_{\text {marine }} \tau_{\text {marine }}}{\tau_{\text {non-dust }}-\tau_{\text {marine }}}
$$

where $f_{\text {marine }}$ is assumed equal to $f_{\text {seasalt }}=0.3$. If $f_{\text {corrected }}$ is smaller than a threshold indicating the sole presence of coarse-mode aerosols, noted $f_{\text {coarse }}$ and equal to 0.35 , the first guess for marine AOD was underestimated and marine AOD is set to $\tau_{\text {non-dust }}$. If however $f_{\text {corrected }}$ is larger than or equal to $f_{\text {coarse }}$, then the first guess for marine AOD is retained and the remaining optical depth is given to the anthropogenic aerosol.

Over land, two components can be identified: anthropogenic and fine-mode natural aerosols. The identification is simply done by using regional anthropogenic fractions, denoted $f_{\text {anth }}$ and defined as the fraction of the total aerosol 
optical depth due to anthropogenic aerosols. Anthropogenic fractions were obtained from Hadley Centre climate model simulations first using emissions of natural aerosols only, then both natural and anthropogenic aerosols under presentday conditions. In those simulations, natural aerosols and aerosol precursors include sea salt, ocean- and land-based dimethyl sulphide, sulphur dioxide from degassing volcanoes, and secondary organic aerosols from biogenic emissions. Biomass-burning aerosols are considered completely anthropogenic. Mineral dust is excluded from those simulations in order to obtain the anthropogenic fraction of $\tau_{\text {non-dust }}$, as required at this stage. Regional values of the anthropogenic fraction are given in Table 1, and their seasonal variations are not taken into account. The anthropogenic fraction is not constrained by observations but is needed as it is known that some of the fine-mode aerosols over land are of natural origin, albeit difficult to discriminate from anthropogenic fine-mode aerosols. Over land, the identification is therefore

$$
\begin{aligned}
\tau_{\text {anth }} & =f_{\text {anth }} \cdot \tau_{\text {non }- \text { dust }} \\
\tau_{\text {fine-mode natural }} & =\left(1-f_{\text {anth }}\right) \cdot \tau_{\text {non-dust }}
\end{aligned}
$$

This simple method implies that anthropogenic and finemode natural aerosol distributions share the same patterns of AOD, which is wrong in regions where the two aerosols have different seasonalities.

Note that the algorithm described above conserves the AOD, and the sum of the four component AODs remains equal to the total AOD in all gridboxes.

Resulting component AODs, averaged over the MACC reanalysis period 2003-2010, are shown in Fig. 2. Distributions show the expected patterns for each aerosol component. Anthropogenic industrial aerosols dominate in North America, Europe, and Asia. Anthropogenic biomass-burning aerosols produce the large AODs seen over Central Africa and South America. Over ocean, the MACC algorithm detects the North American pollution outflow over the North Atlantic and the biomass-burning plume transported from Southern Africa. However, the small background of anthropogenic AODs in the Southern Ocean is suspected to originate from misidentifications with fine-mode marine aerosols. Marine AOD is maximum over mid-latitude oceans where near-surface wind speeds are large. Obtaining reasonable patterns gives confidence in the algorithm but is not a validation. Unfortunately, there is no purely observational dataset currently available for validating component aerosol distributions.

Section 7 describes the Monte-Carlo analysis of uncertainties used in this study. Uncertainties in the component AODs first arise from uncertainties in the retrievals of total AOD that is assimilated into the model, and errors in the forward modelling of total and component AODs. In addition, the parameters used in the identification algorithm described above also contribute to the uncertainty. For the anthropogenic AOD, the Monte-Carlo analysis yields a relative standard deviation of $18 \%$ on a global average (16\% over ocean, $23 \%$ over land). Those values are smaller than the estimated $60 \%$ on the anthropogenic AOD in Yu et al. (2006). This is because the Monte-Carlo analysis accounts for compensating errors between the parameters of the identification algorithm, and between gridboxes. In addition, Yu et al. (2006) relies on an identification method where the FMF is used directly in a formula giving the anthropogenic AOD. The method used in this study only compares the FMF to a threshold and the impact of the FMF uncertainty is reduced, since it propagates only when it is large enough to bring the FMF below the threshold $f_{\text {coarse }}$.

Table 2 gives total and component AODs and their uncertainties for the MACC estimates. The globally and annually-averaged total and anthropogenic AODs at $0.55 \mu \mathrm{m}$ are $0.180 \pm 0.030$ and $0.073 \pm 0.013$, respectively. Marine aerosols represent $32 \pm 4 \%$ of globally-averaged total AOD, but dominate over oceans. On a global average, mineral dust and fine-mode natural aerosols contribute $22 \pm 6 \%$ and $5 \pm 2 \%$ respectively. Anthropogenic aerosols contribute most, at $41 \pm 4 \%$ of the total AOD. That fraction is larger than the $23 \%$ obtained by the analysis of the year 2002 based on MODIS collection 5 retrievals made by Bellouin et al. (2008). The MACC anthropogenic AOD over cloudfree oceans of $0.062 \pm 0.010$ is also larger than the satellite estimate of 0.035 by Yu et al. (2009) for the period 2001-2007. Compared to those previous estimates, larger anthropogenic AODs in MACC originate from larger anthropogenic transport across the North Atlantic and North Pacific oceans from March to August, and over the Indian and Southern oceans from September to November. Also, possible mis-identifications with marine aerosols over the oceanic regions where wind speeds are large, such as the North Atlantic, North Pacific, and Southern oceans, lead to broad areas where anthropogenic AODs are between 0.05 to 0.1 , which contribute to increase the global average. On the modelling side, AeroCom models simulate an anthropogenic AOD of 0.029 , or $25 \%$ of their present-day total AOD (Schulz et al., 2006). However, AeroCom defines anthropogenic AOD as the difference between total AOD in pre-industrial and present-day conditions: this is not the same as the present-day anthropogenic AOD derived in MACC. Bellouin et al. (2008) used the Hadley Centre climate model, where aerosol and precursor emissions for the year 1860 were used to represent pre-industrial aerosols, to find that the optical depth of present-day anthropogenic aerosols is 1.25 times larger than the change in total AOD between preindustrial and present-day conditions. Using that factor, AeroCom models would simulate a present-day anthropogenic AOD of $0.036,31 \%$ of their present-day total AOD. That fraction is again smaller than the $41 \%$ obtained in this study. 
Table 2. Total and component aerosol optical depths (AOD), absorption aerosol optical depths (AAOD), direct radiative effects (DRE), and direct radiative effect efficiencies (DREE), for the MACC re-analysis over the period 2003-2010, in global, ocean, and land averages. Optical depths are given at $0.55 \mu \mathrm{m}$. Direct effects, in $\mathrm{Wm}^{-2}$, and efficiencies, in $\mathrm{Wm}^{-2}$ per unit AOD, are for the shortwave spectrum and cloud-free conditions, and given at the top of atmosphere (TOA), surface, and within the atmosphere. See Sect. 7 for calculation of uncertainties.

\begin{tabular}{|c|c|c|c|c|c|c|c|}
\hline \multirow[b]{2}{*}{ Aerosol type } & \multirow[b]{2}{*}{ AOD } & \multirow[b]{2}{*}{ AAOD } & \multicolumn{2}{|c|}{ TOA } & \multicolumn{2}{|c|}{ Surface } & \multirow{2}{*}{$\begin{array}{c}\text { Atmosphere } \\
\text { DRE }\end{array}$} \\
\hline & & & DRE & DREE & DRE & DREE & \\
\hline & \multicolumn{7}{|c|}{ Global } \\
\hline Total & $0.180 \pm 0.030$ & $0.008 \pm 0.002$ & $-7.3 \pm 1.3$ & -41 & $-10.8 \pm 1.9$ & -60 & +3.5 \\
\hline Anthropogenic & $0.073 \pm 0.013$ & $0.007 \pm 0.001$ & $-2.9 \pm 0.5$ & -40 & $-5.8 \pm 1.1$ & -80 & +3.0 \\
\hline Mineral dust & $0.043 \pm 0.014$ & $0.001 \pm 0.001$ & $-1.4 \pm 0.4$ & -33 & $-1.9 \pm 0.6$ & -44 & +0.5 \\
\hline Marine & $0.055 \pm 0.016$ & $0.000 \pm 0.000$ & $-2.8 \pm 0.8$ & -51 & $-2.8 \pm 0.8$ & -51 & +0.0 \\
\hline \multirow[t]{2}{*}{ Fine-mode natural } & $0.009 \pm 0.004$ & $0.000 \pm 0.000$ & $-0.3 \pm 0.2$ & -33 & $-0.3 \pm 0.2$ & -33 & +0.0 \\
\hline & \multicolumn{7}{|c|}{ Ocean } \\
\hline Total & $0.170 \pm 0.030$ & $0.007 \pm 0.001$ & $-7.7 \pm 1.5$ & -45 & $-10.6 \pm 1.9$ & -62 & +2.9 \\
\hline Anthropogenic & $0.062 \pm 0.010$ & $0.006 \pm 0.001$ & $-2.8 \pm 0.5$ & -45 & $-5.3 \pm 0.9$ & -85 & +2.6 \\
\hline Mineral dust & $0.030 \pm 0.010$ & $0.001 \pm 0.001$ & $-1.0 \pm 0.4$ & -33 & $-1.3 \pm 0.6$ & -43 & +0.3 \\
\hline Marine & $0.078 \pm 0.022$ & $0.000 \pm 0.000$ & $-3.9 \pm 1.1$ & -50 & $-4.0 \pm 1.1$ & -51 & +0.1 \\
\hline \multirow[t]{2}{*}{ Fine-mode natural } & \multicolumn{7}{|c|}{ N/A } \\
\hline & \multicolumn{7}{|c|}{ Land } \\
\hline Total & $0.203 \pm 0.030$ & $0.010 \pm 0.003$ & $-6.4 \pm 1.0$ & -32 & $-11.5 \pm 1.9$ & -57 & +5.1 \\
\hline Anthropogenic & $0.098 \pm 0.023$ & $0.008 \pm 0.003$ & $-3.1 \pm 0.7$ & -32 & $-7.0 \pm 1.7$ & -71 & +3.9 \\
\hline Mineral dust & $0.074 \pm 0.014$ & $0.001 \pm 0.001$ & $-2.4 \pm 0.5$ & -32 & $-3.3 \pm 0.7$ & -45 & +0.9 \\
\hline Marine & \multicolumn{7}{|c|}{ N/A } \\
\hline Fine-mode natural & $0.032 \pm 0.013$ & $0.001 \pm 0.001$ & $-0.9 \pm 0.6$ & -28 & $-1.1 \pm 0.8$ & -34 & +0.2 \\
\hline
\end{tabular}

\section{Aerosol direct effect and forcing}

\subsection{Aerosol direct effect}

Now that component AODs are known, radiative transfer calculations are needed to obtain direct effects. DREs are computed for all four aerosol components identified by the algorithm with respect to an atmosphere containing no aerosols. Radiative transfer calculations require the knowledge of the aerosol optical properties, the surface albedo, and the cloud and aerosol vertical profiles. Aerosol radiative effects and forcing are only estimated in the shortwave spectrum.

Aerosol optical properties are derived from size distributions and single-scattering albedos retrieved from groundbased sun-photometer measurements at specific sites worldwide (Dubovik et al., 2002). Such sites are assumed to be representative either of a given aerosol type (mineral dust, marine, and fine-mode natural aerosols) or of a regional anthropogenic aerosol. Representative sites and single-scattering albedo values are given in Table 1 . The regions are the same as used for prescribing the anthropogenic fraction in the previous section. The fine-mode natural aerosol is assumed to have a single-scattering albedo of 0.98 at $0.55 \mu \mathrm{m}$ and the same size distribution as the North American aerosol. Prescribed aerosol absorption properties yield the seasonal distributions of absorption AOD shown in Fig. 3. Averages and uncertainties for the global, ocean, and land domains are given in Table 2. Anthropogenic aerosols contribute almost $90 \%$ of total absorption, which is located predominantly in the Southern Hemisphere and Asia. The South American and African regions, which are dominated by biomassburning emissions, account for $62 \%$ of anthropogenic absorption. On a global average, the single-scattering albedo is 0.96 for total aerosol, 0.90 for anthropogenic aerosols. Note however that the AERONET measurements used to prescribe anthropogenic absorption were taken close to the aerosol sources. Aerosol absorption tends to decrease with transport and ageing, especially for biomass-burning aerosols (Abel et al., 2003). The MACC estimates do not account for those changes, and likely overestimate anthropogenic absorption. However, mineral dust and anthropogenic absorption AODs estimated in this study are in good agreement with the assessment of Bond et al. (2013), who derived from an analysis of AERONET retrievals and AeroCom modelling an absorption AOD of 0.006 for fossil-fuel and biomass-burning black carbon aerosols, and 0.001 for mineral dust aerosols.

Surface albedo is computed over ocean as a function of solar zenith angle and $10 \mathrm{~m}$ wind speed (Cox and Munk, 1954) and taken from the IFS over land in the visible and nearinfrared spectra.

The aerosol vertical profile is not taken from the IFS since that aspect of the model is unaffected by data assimilation. 


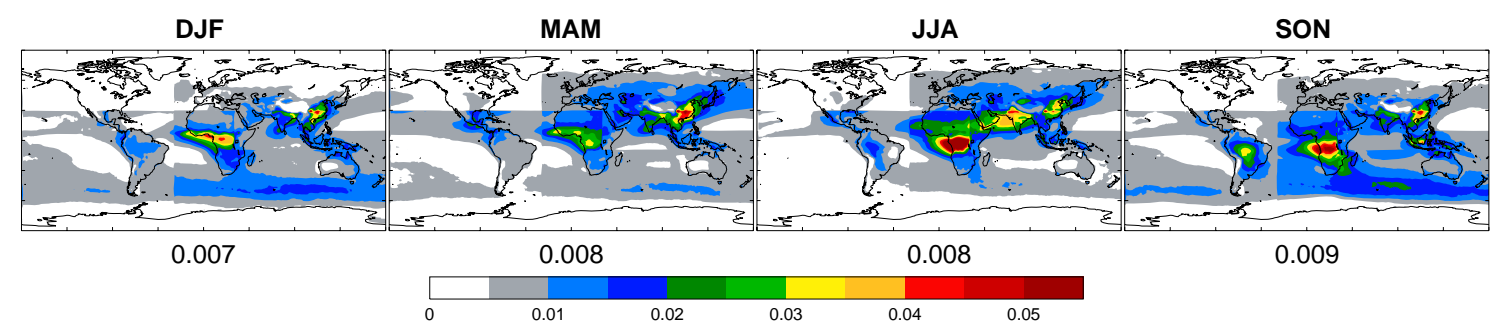

Fig. 3. Seasonal distributions of total absorption AOD at $0.55 \mu \mathrm{m}$ as derived from the MACC re-analysis over 2003-2010. Global averages are given by the numbers below each panel.

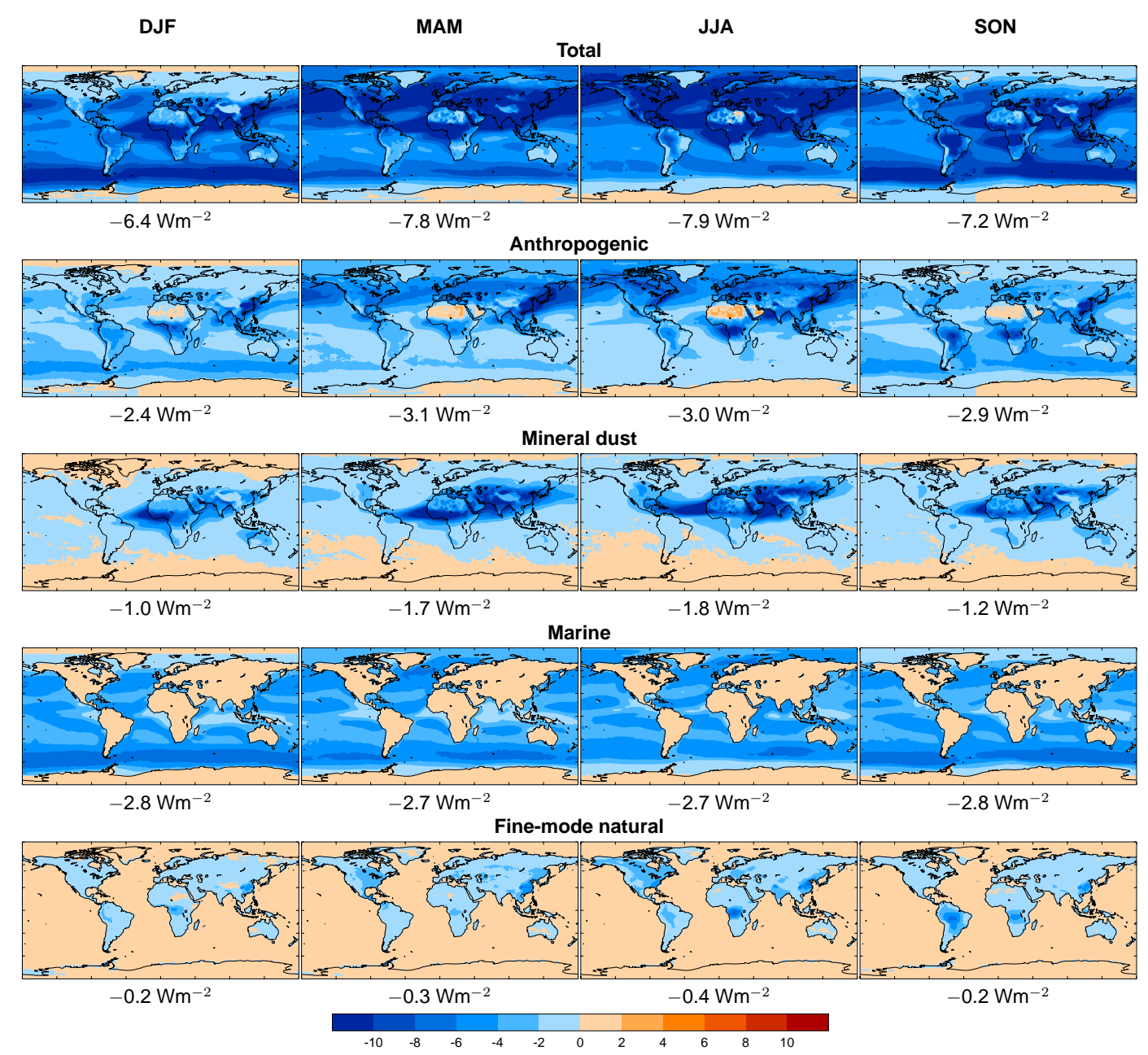

Fig. 4. Seasonal distributions of shortwave direct radiative effect in cloud-free sky at the top of the atmosphere, in $\mathrm{Wm}^{-2}$, as derived from the MACC re-analysis over 2003-2010. From top to bottom, the direct effect is for total, anthropogenic, mineral dust, marine, and fine-mode natural aerosols. Global averages are given by the numbers below each panel.

Rather, it is assumed that natural aerosols are located in the first kilometre of the atmosphere, below a layer of anthropogenic aerosols. For the cloud-free DRE, the impact of this assumed vertical profile on shortwave radiative fluxes is small: the change in molecular scattering above the aerosol layer is a second-order effect. It is worth noting however that the vertical profile prescribed in this way is not consistent with the hygroscopic growth experienced by aerosols at the time of the MODIS retrieval of total AOD. A similar inconsistency happens during the assimilation process.

Radiative transfer calculations are performed using a discrete-ordinate solver (Key and Schweiger, 1998), with 24 shortwave wavebands and 24 streams. The $24 \mathrm{~h}$ averaged DRE is computed by integrating the instantaneous radiative 
effects over the solar zenith angles as a function of latitude and day of the year, with 10 timesteps per day.

Total and component DREs in the shortwave spectrum in cloud-free sky at the TOA, averaged over the MACC reanalysis period, are shown in Fig. 4. Component DREs follow the distribution of the corresponding component AOD but with strengths modulated by aerosol absorption properties and surface albedo. In both hemispheres, total DRE is stronger during the summer when incoming solar radiation is larger. Consequently, the globally-averaged total DRE is stronger during the Northern Hemisphere summer, as more aerosols are located in the Northern Hemisphere. DREs and direct radiative effect efficiencies (DREEs) are given in Table 2 for TOA and surface, averaged over the MACC reanalysis period. Efficiencies are within previously-published ranges (Anderson et al., 2005; Yu et al., 2006). Varying efficiencies reflect the different absorbing properties of the different species. At the TOA, DREE decreases with increasing aerosol absorption, since absorption does not reflect radiation back to space. In constrast, at the surface, DREE increases with increasing aerosol absorption, since none of the absorbed radiation reaches the surface, unlike scattered radiation that may still do so from another direction. Differences in surface albedo where some species are preferentially located also matter. At the TOA, anthropogenic and marine aerosols contribute almost equally to the total direct effect, at around $40 \%$ each. This is because marine aerosols are more efficient than anthropogenic aerosols at exerting a direct effect at the TOA, and their contribution of $39 \%$ to the total direct effect is therefore more than their contribution of $32 \%$ to the total AOD.

The difference between TOA and surface forcing gives the amount of energy absorbed in the atmosphere because of the aerosols, sometimes termed atmospheric forcing and estimated here at $+3.5 \mathrm{Wm}^{-2}$ over the period 2003-2010. Anthropogenic aerosols absorption represents $+3.0 \mathrm{Wm}^{-2}$ $(86 \%)$ of the total, with the remainder being contributed by mineral dust aerosols. As expected from the distribution of anthropogenic aerosols, most of aerosol atmospheric forcing is located over land.

Uncertainties in the DRE arise from uncertainties in component optical depths and uncertainties in the prescribed regional optical properties, especially absorption. Section 7 details how those uncertainties are included in the Monte-Carlo analysis, which yields a relative standard deviation of $17 \%$ on global-averaged anthropogenic DRE in cloud-free conditions at the TOA.

In Yu et al. (2006), the cloud-free DRE is estimated over oceans at $-5.5 \pm 0.2 \mathrm{Wm}^{-2}$ at the TOA and $-8.8 \pm 0.7 \mathrm{Wm}^{-2}$ at the surface, where uncertainties are a measure of diversity among different satellite-based methods rather than an actual measure of the overall uncertainty as attempted in this study. The corresponding MACC radiative forcings, listed in Table 2, are stronger at $-7.7 \pm 1.5$ and $-10.6 \pm 1.9 \mathrm{Wm}^{-2}$, respectively. In addition to the prob- lem of incomplete sampling of aerosol distributions by satellite products, the total AOD over ocean is larger in MACC, at 0.17, than in Yu et al. (2006), at 0.14: in the same environmental conditions, larger AODs exert stronger DREs. Also, the MACC total DRE is computed as the sum of the component DREs: this method neglects the coupling between the DRE of different species and overestimates the DRE by a few tenths of $\mathrm{Wm}^{-2}$, the exact value depending on the relative vertical profiles of the different aerosol species. The agreement is slightly better over cloudfree land, where Yu et al. (2006) gives $-4.9 \pm 0.7 \mathrm{Wm}^{-2}$ at the TOA and $-11.8 \pm 1.9 \mathrm{Wm}^{-2}$ at the surface, for a total AOD of 0.220 . Corresponding MACC values are $-6.4 \pm 1.0$ and $-11.5 \pm 1.9 \mathrm{Wm}^{-2}$, for a total AOD of 0.203 . On a global scale and in cloud-free conditions, the MACC estimates of total DRE of $-7.3 \pm 1.3 \mathrm{Wm}^{-2}$ at the TOA and $-10.8 \pm 1.9 \mathrm{Wm}^{-2}$ at the surface compare well with those by Kim and Ramanathan (2008), who obtained $-6.0 \pm 1.0 \mathrm{Wm}^{-2}$ and $-11.0 \pm 2.0 \mathrm{Wm}^{-2}$, respectively.

\subsection{Aerosol direct forcing}

The direct forcing is computed for anthropogenic aerosols as the difference between an atmosphere containing all aerosols and an atmosphere containing natural aerosols only. In effect, natural aerosols therefore act as a proxy for pre-industrial aerosols. Calculations are similar to that for the direct effect, as described in the previous section. One difference worth noting is the impact of the prescribed vertical profile. For the direct forcing, the direct effect of natural aerosols modifies the radiative fluxes experienced by anthropogenic aerosols, and therefore their forcing. The assumption that natural aerosols are located below the anthropogenic layer effectively increases the reflectance of the underlying atmosphere, and makes the DRF less negative than when other vertical profiles are used. The weakening of the DRF is large when anthropogenic aerosols are absorbing. The MACC DRF is also underestimated when natural aerosols in fact overlie the anthropogenic layer, for example in situations of long-range transport of mineral dust aerosols above a biomass-burning plume.

The top row of Fig. 5 shows the cloud-free estimates of DRF, seasonally over the period 2003-2010. The global, multi-annual average is $-2.5 \pm 0.5 \mathrm{Wm}^{-2}$ at the TOA, and $-5.5 \pm 1.0 \mathrm{Wm}^{-2}$ at the surface. The Monte-Carlo uncertainty analysis described in Sect. 7 has again been used to evaluate those standard deviations, and Table 3 lists the ocean and land averages. Direct forcing is typically stronger over continents and in the Northern Hemisphere, where most anthropogenic sources are located, and in Northern Hemisphere summer, when both anthropogenic AOD and incoming solar radiation are largest.

The aerosol DRF is scaled from cloud-free to all-sky conditions by multiplying, in each gridbox, the cloud-free DRF by the cloud-free fraction simulated by the IFS, and 


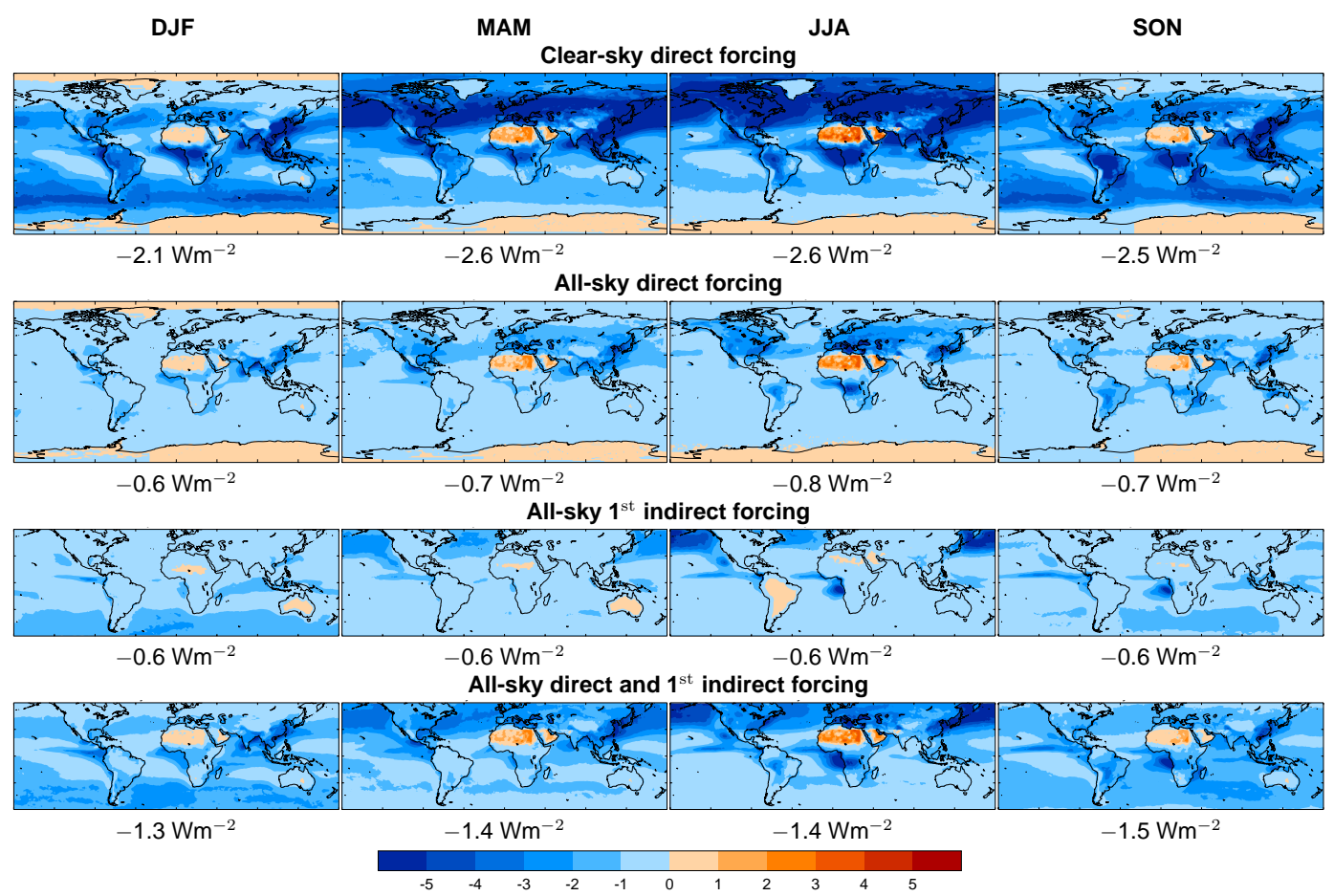

Fig. 5. Seasonal distributions of shortwave aerosol forcing at the top of the atmosphere, in $\mathrm{Wm}^{-2}$, as derived from the MACC re-analysis over 2003-2010. From top to bottom, clear-sky (or cloud-free) direct forcing, all-sky direct forcing, all-sky first indirect forcing, and the sum of all-sky direct and first indirect forcing. First indirect forcing is not estimated poleward of $60^{\circ}$ latitude. Global averages are given by the numbers below each panel.

Table 3. Anthropogenic aerosol direct radiative forcing (DRF) in cloud-free and all-sky conditions, and first indirect radiative forcing (IRF) and total aerosol radiative forcing (RF) in all-sky conditions, as derived from the MACC re-analysis over 2003-2010. All values are in Wm ${ }^{-2}$ at the top of the atmosphere (TOA), unless where stated, for the shortwave spectrum only. See Sect. 7 for calculations of uncertainties. Values are global for the DRF, but for $60^{\circ} \mathrm{N}-60^{\circ} \mathrm{S}$ for the IRF and RF.

\begin{tabular}{lccc}
\hline & Global & Ocean & Land \\
\hline Cloud-free DRF & $-2.5 \pm 0.5$ & $-2.4 \pm 0.4$ & $-2.5 \pm 0.7$ \\
Cloud-free DRF (surface) & $-5.5 \pm 1.0$ & $-5.1 \pm 0.9$ & $-6.5 \pm 1.6$ \\
All-sky DRF & $-0.7 \pm 0.2$ & $-0.7 \pm 0.1$ & $-0.8 \pm 0.3$ \\
All-sky IRF & $-0.6 \pm 0.4$ & $-0.8 \pm 0.5$ & $-0.2 \pm 0.2$ \\
All-sky RF & $-1.4 \pm 0.5$ & $-1.5 \pm 0.5$ & $-1.2 \pm 0.4$ \\
\hline
\end{tabular}

accounting for uncertainties in both. Doing so yields an allsky DRF of $-0.7 \pm 0.2 \mathrm{Wm}^{-2}$ (see Table 3 ) and is equivalent to assuming a DRF of zero in cloudy sky. The resulting probability density function (PDF) is shown in Fig. 6. Assuming no DRF in cloudy sky is wrong, however, as aerosols overlying clouds may exert a sizeable DRF, which is positive for absorbing aerosols, as recently estimated from remote sensing off the Western African coast (de Graaf et al., 2012). AeroCom models simulate a globally-averaged cloudy-sky DRF of -0.2 to $+0.3 \mathrm{Wm}^{-2}$, with a median value of $+0.02 \pm 0.16 \mathrm{Wm}^{-2}$ (Schulz et al., 2006). Combining that estimate in a Monte-Carlo framework with the MACC PDFs of clear-sky DRF and cloud cover yields the same best estimate of all-sky DRF as before, $-0.7 \mathrm{Wm}^{-2}$, but the standard deviation increases from 0.2 to $0.3 \mathrm{Wm}^{-2}$.

The MACC estimate of all-sky DRF has to be corrected further before comparing against model and IPCC estimates. This correction addresses the difference between presentday natural aerosols and pre-industrial aerosols when acting as the reference state for the forcing. Bellouin et al. (2008) applied both reference states in the Hadley Centre climate model and found that, for the same present-day anthropogenic aerosol distribution, the all-sky DRF is 1.6 times weaker when pre-industrial aerosols, represented by the year 1860, are used as a reference. Using that factor, the MACC estimate of all-sky DRF with respect to pre-industrial 


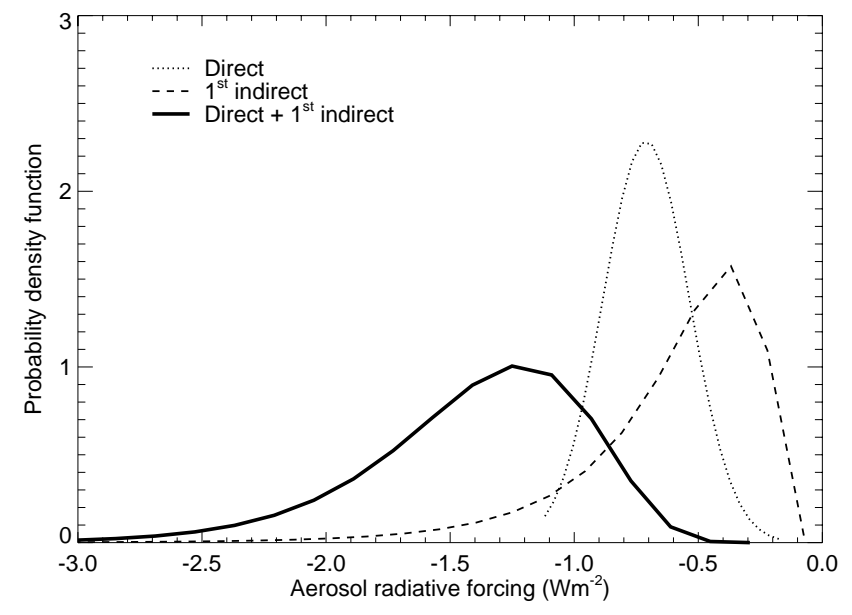

Fig. 6. Probability density functions of direct (dotted line) and first indirect (dashed line) aerosol radiative forcing, and their sum (solid line), for the period 2003-2010. See Sect. 7 for the description of the Monte-Carlo method used to derive those functions. Radiative forcings are for the shortwave spectrum only and given in $\mathrm{Wm}^{-2}$.

becomes $-0.4 \mathrm{Wm}^{-2}$. The standard deviation of $0.3 \mathrm{Wm}^{-2}$ still applies, but does not include the uncertainty in the preindustrial reference. The best estimate is within the AeroCom (Schulz et al., 2006) and IPCC (Forster et al., 2007) estimates of $-0.2 \pm 0.2$ and $-0.4 \pm 0.4 \mathrm{Wm}^{-2}$, respectively.

Finally, the DRF exerted by anthropogenic absorption is estimated by making anthropogenic aerosols non-absorbing in the six regions used to prescribe single-scattering albedo, and taking the difference with the standard DRF estimates. Doing so yields a DRF due to anthropogenic absorption of +1.0 and $-1.9 \mathrm{Wm}^{-2}$ in cloud-free sky at the TOA and surface, respectively, and $+0.4 \mathrm{Wm}^{-2}$ in all-sky at the TOA. Those estimates do not include the cloudy-sky contribution to the DRF, and are with respect to present-day natural aerosols. According to Bond et al. (2013), black carbon DRF with respect to pre-industrial conditions represents $80 \%$ of present-day black carbon DRE. Using that factor to correct for differences in present-day natural and pre-industrial aerosols, and attributing the MACC anthropogenic absorption to black carbon aerosols only, yields a DRF due to anthropogenic absorption of $+0.3 \mathrm{Wm}^{-2}$. Cloudy-sky absorption DRF would make that estimate more strongly positive, but cannot be quantified at this stage.

\section{Aerosol indirect forcing}

The IRF is the change in cloud albedo exerted by a change in cloud droplet number concentration due to anthropogenic aerosols. The MACC estimate follows the method of Quaas et al. (2008) where IRF is computed as:

$\mathrm{IRF}=f_{\text {cld,liq }} \cdot \bar{F}_{\downarrow} \cdot \frac{\partial \alpha}{\partial \ln N_{d}} \cdot \frac{\partial \ln N_{d}}{\partial \ln \tau} \cdot\left(\ln \tau-\ln \tau_{\text {nat }}\right)$
Table 4. Seasonal and regional sensitivities $\partial \ln N_{d} / \partial \ln \tau$ of cloud droplet number concentrations $N_{d}$ to changes in aerosol optical depth $\tau$ used in this study. The 14 regions are as defined in Fig. 1 of Quaas et al. (2008). $\sigma$ is the standard deviation as used in the Monte-Carlo uncertainty analysis (Section 7) and applies to all seasons. Note ${ }^{\mathrm{a}}$ : Except in latitude band $20-30^{\circ} \mathrm{S}$ where $\sigma$ is 0.202 .

\begin{tabular}{lccccc}
\hline Region & DJF & MAM & JJA & SON & $\sigma$ \\
\hline Ocean & & & & & \\
\hline North Pacific Ocean & 0.355 & 0.266 & 0.328 & 0.297 & 0.163 \\
North Atlantic Ocean & 0.355 & 0.318 & 0.261 & 0.351 & 0.163 \\
Tropical Pacific Ocean & 0.232 & 0.232 & 0.243 & 0.261 & 0.163 \\
Tropical Atlantic Ocean & 0.270 & 0.282 & 0.468 & 0.317 & 0.163 \\
Tropical Indian Ocean & 0.334 & 0.237 & 0.159 & 0.297 & 0.163 \\
South Pacific Ocean & 0.159 & 0.175 & 0.185 & 0.120 & $0.163^{\mathrm{a}}$ \\
South Atlantic Ocean & 0.216 & 0.225 & 0.312 & 0.150 & $0.163^{\mathrm{a}}$ \\
South Indian Ocean & 0.166 & 0.235 & 0.308 & 0.181 & $0.163^{\mathrm{a}}$ \\
\hline Land & & & & & \\
\hline North America & 0.115 & 0.098 & 0.103 & 0.084 & 0.109 \\
Europe & 0.112 & 0.139 & 0.180 & 0.074 & 0.109 \\
Asia & 0.159 & 0.099 & 0.112 & 0.107 & 0.109 \\
Africa & 0.079 & 0.086 & 0.106 & 0.114 & 0.109 \\
South America & 0.090 & 0.004 & -0.002 & 0.060 & 0.109 \\
Oceania & -0.004 & -0.020 & 0.048 & 0.066 & 0.109 \\
\hline
\end{tabular}

where:

- $f_{\text {cld,liq }}$ is the projected fractional cover of liquid clouds, that is clouds that have liquid water rather than ice at their tops and are not obscured by overlying ice clouds. In this study, cloud cover is the low-level cloud cover, for clouds whose top pressures are above $680 \mathrm{hPa}$, as diagnosed by the IFS. No attempts are made to estimate the IRF of ice clouds. In order to avoid having ice clouds among the low-level clouds, indirect forcing is not calculated for regions poleward of $60^{\circ}$;

- $\bar{F}_{\downarrow}$ is the daily-mean incoming solar radiative flux, in $\mathrm{Wm}^{-2}$, at the top of the atmosphere, computed from the declination angle and Earth-Sun distance corresponding to the Julian day of the year and from the length of day corresponding to the latitude and day of the year;

- $\alpha$ is the broadband shortwave planetary albedo;

- $N_{d}$ is the liquid CDNC;

$-\tau$ is the AOD;

- $\tau_{\text {nat }}$ is the natural AOD, derived from the total and anthropogenic AOD as estimated above.

The two partial derivatives are the key terms in the estimate of IRF and are taken from the statistical analysis of satellite retrievals performed by Quaas et al. (2008).

The first derivative, $\partial \alpha / \partial \ln N_{d}$, is the susceptibility of liquid cloud albedo to a relative change in CDNC. This susceptibility depends on cloud fraction and cloud optical depth 
and is computed using the statistical method of Quaas et al. (2008), except that the cloud cover used here is simulated by the IFS. IFS does not diagnose cloud optical depth, however, and it is instead computed from the diagnosed cloud liquid water path assuming vertically homogeneous clouds with an effective droplet radius of $14 \mu \mathrm{m}$.

The second derivative is the sensitivity of CDNC to a relative change in AOD. In principle, CDNC is a function of cloud condensation nuclei (CCN) number concentrations and cloud-scale updraft velocity as described by Köhler theory. At the large scale however, a parameterisation needs to reflect the bulk effect of aerosol concentrations on cloud droplet number concentrations (e.g. Lohmann et al., 2007). Here we choose to use AOD as a proxy for CCN number concentrations (Andreae, 2009). Since relative changes are considered, it is sufficient if CCN scale with AOD.

There has recently been a debate in the literature on the validity of the statistical approach used to estimate the IRF (Penner et al., 2011; Quaas et al., 2011). Specifically, it was questioned whether the sensitivity of CDNC for a perturbation of AOD is a metric able to capture the real change in CDNC from pre-industrial to present-day times (McComiskey et al., 2009). There are suggestions that the choice of AOD as a proxy for CCN number concentrations (Andreae, 2009) leads to an underestimation of aerosol indirect radiative forcing. Statistics sampled from present-day variability in AOD and CDNC may not be sufficient to sample the full difference between pre-industrial and presentday conditions (Penner et al., 2011). Inversely, Grandey and Stier (2010) suggest that the statistical method by Quaas et al. (2008), also used here, leads to an overestimation. Given current knowledge, the method is considered valid for this work, but an uncertainty assessment is important.

In the evaluation of Eq. (7), the susceptibility of cloud albedo to CDNC changes and the sensitivity of CDNC to AOD changes are taken from an analysis of satellite observations, where solar broadband albedo is taken from CERES (Wielicki et al., 1996; Loeb et al., 2002) retrievals, and AOD and cloud properties are retrieved by MODIS (Remer et al., 2005; Minnis et al., 2003). CDNC is estimated from cloud optical depth and cloud effective radius assuming adiabatic clouds, following Quaas et al. (2006). The partial derivatives are evaluated as in Quaas et al. (2008) for fourteen different oceanic and continental regions, and the four seasons of the year. Seasonal and regional sensitivities of CDNC to AOD changes are given in Table 4.

Seasonal distributions of all-sky IRF at TOA are shown in the third row of Fig. 5. IRF is stronger where aerosols interact with low, maritime clouds. This includes the stratocumulus decks off the coasts of Namibia, California, and Peru. Over land, IRF is weak. On a multi-annual, global average, the best estimate of IRF is $-0.6 \mathrm{Wm}^{-2}$ (Table 3). This estimate is stronger than the $-0.2 \mathrm{Wm}^{-2}$ derived from satellite data by Quaas et al. (2008) because the anthropogenic AOD is larger in MACC, especially at low latitudes over the oceans where cloud susceptibility is large. In addition, cloud albedo susceptibilities obtained from cloud distributions in the MACC re-analysis are typically larger than those derived from MODIS retrievals of cloud optical depth. As done for the DRF, the IRF uncertainty is derived by the Monte-Carlo analysis described in Sect. 7. Standard deviation on the IRF is $0.4 \mathrm{Wm}^{-2}$. However, because additional aerosols can only increase or leave unchanged the CDNC, but not decrease it, the IRF cannot be positive. Its PDF is therefore asymmetric, being skewed towards zero, as shown on Fig. 6 . The overall range of IRF estimates is -2.0 to $-0.1 \mathrm{Wm}^{-2}$, encompassing both stronger and weaker values than the 5-95\% confidence range of -1.8 to $-0.3 \mathrm{Wm}^{-2}$ assessed by the IPCC (Forster et al., 2007).

\section{Total aerosol forcing}

Total aerosol forcing is defined as the sum of DRF and IRF. Seasonal distributions of all-sky total forcing at the TOA over the period 2003-2010 are shown in the bottom row of Fig. 5. Total forcing is slightly dominated by DRF and therefore tends to be located over land. IRF dominates over oceanic stratocumulus deck regions. Table 3 gives the best estimate of globally-averaged total forcing at $-1.4 \pm 0.5 \mathrm{Wm}^{-2}$. This value is uncorrected for differences between present-day natural and pre-industrial aerosol distributions because such a correction has only been applied to the DRF.

The PDFs for DRF and IRF estimates translate, if combined in a Monte-Carlo framework and assumed independent, to an uncertainty range of -3.0 to $-0.3 \mathrm{Wm}^{-2}$ for the total forcing (Fig. 6). This range is very similar to the distribution function obtained by the fourth IPCC assessment report, where probability peaks at $-1 \mathrm{Wm}^{-2}$ but is non-zero over the range -3.0 to $0 \mathrm{Wm}^{-2}$ (see Fig. 2.20 of Forster et al., 2007). The MACC estimates can therefore be interpreted as an independently-derived confirmation of the IPCC range, although the uncertainty range has not been reduced.

\section{Uncertainty analysis}

The standard deviations given in this study originate from a Monte-Carlo method, whereby uncertain input distributions and parameters are sampled randomly to obtain PDFs of component AODs and radiative forcing. Such a method allows a robust assessment of uncertainties, because it is applied within the MACC aerosol forcing algorithm, allows for the full propagation of uncertainties from component AODs to radiative forcing, and accounts for compensating errors. The parameter space is sampled by 250 Monte-Carlo experiments, which consist in applying the aerosol identification algorithm, followed by DRF and IRF estimates, on daily MACC re-analysis aerosol products for the year 2003. Running 250 additional experiments does not change statistics above the one decimal-place precision used here to report 
results. Unless otherwise stated, PDFs of uncertain input distributions and parameters follow lognormal distributions, because most variables used cannot be negative. It is also ensured that variables remain in their physical boundaries, e.g. FMF, cloud cover, and single-scattering albedos always remain bounded by 0 and 1 . The choice of the shape of the PDF is subjective and made in the absence of better characterised PDFs. It influences the shape of the PDFs produced by the Monte-Carlo method. Lognormal distributions are characterised by a mean and a standard deviation. For input distributions, the mean is the value simulated by the ECMWF IFS in each gridbox. For parameters, the mean is the value used in the standard experiment and given in the previous sections.

Uncertain input distributions are the total AOD, mineral dust AOD, non-dust FMF, and cloud cover simulated in the MACC aerosol re-analysis. Random noise is introduced at two levels: globally, to represent the uncertainty in the global average, and in each gridbox, to represent the uncertainty in the retrieval assimilated in the re-analysis and/or simulated by the model. Global noise is assumed to be normally distributed and one random choice is made for each parameter in each Monte-Carlo experiment. Global-averaged total AOD at $0.55 \mu \mathrm{m}$ is given a standard deviation of 0.03 , taken from the spread in AOD retrievals from various satellite instruments presented in Fig. 5 of Kinne et al. (2006). For mineral dust AOD at $0.55 \mu \mathrm{m}$, the standard deviation is 0.014 , following the 14 AeroCom models listed in Table 4 of Kinne et al. (2006). The same models are used again to obtain the standard deviation on global-averaged non-dust FMF at $0.55 \mu \mathrm{m}$, which is 0.1. For fractional cloud cover, Stubenrauch et al. (2012) report a standard deviation on the global average of 0.03 for clouds with optical depth larger than 0.1 , and this value is used here. Gridbox-level noise is lognormal to avoid negative values and is applied multiple times in each gridbox over the course of a Monte-Carlo experiment. The standard deviation in MODIS retrievals of total AOD at $0.55 \mu \mathrm{m}$ has been confirmed by validation studies (Remer et al., 2005; Levy et al., 2007) at $0.03+0.05 \tau$ over ocean and $0.05+0.15 \tau$ over land, where $\tau$ denotes the total AOD. The re-analysis is expected to have smaller uncertainties than the forward model and the assimilated data, but using the uncertainties of the latter gives an upper bound. The gridbox-level standard deviation for mineral dust AOD is assumed to be the same as that for total AOD. When computing noisy values, mineral dust AOD is bounded by the total AOD, and non-dust AOD is computed as the residual in order to ensure that AOD is not lost or created. For non-dust FMF and fractional cloud cover, gridbox-level standard deviations are taken at 0.25 and 0.1 , respectively, so that a large fraction of the 0 to 1 interval is covered by the PDFs.

Uncertain parameters used to derive the MACC component AODs are the slope and offset used to compute the first guess of marine AOD (Eq. 1), the prescribed FMF of marine aerosols used in Eq. (4), the threshold on FMF $f_{\text {coarse, }}$ and the six regional anthropogenic fractions listed in Table 1. For each Monte-Carlo experiment, one random choice is made for each of those parameters. Standard deviations on the marine AOD slope and offset are taken at 0.001 and 0.005 , respectively, in order to cover the various empirical formulas listed in Table 1 of Smirnov et al. (2003). For the other parameters, standard deviations are chosen so that a wide range of values is covered: 0.2 for the marine FMF, 0.05 for the threshold on FMF, and 0.2 for each of the regional anthropogenic fractions.

Uncertain parameters used in the estimation of aerosol DRF are the six regional SSAs listed in Table 1. Their standard deviation is 0.03 , so that the 4-sigma interval covers a large portion of the realistic range of SSAs. The six regional SSAs are varied independently, with one random choice for each in each Monte-Carlo experiment.

Uncertain parameters used in the estimation of aerosol IRF are the cloud effective radius used in computing cloud optical depth, and the regional and seasonal cloud albedo susceptibilities and CDNC sensitivities. For each Monte-Carlo experiment, one random choice is made for each of those parameters. Regional parameters are varied independently. For parameters that also vary seasonally, the same noise is applied for all seasons. Standard deviation in cloud effective radius is taken at $2.5 \mu \mathrm{m}$, as reported for liquid clouds (Minnis et al., 2011). Standard deviations on cloud albedo susceptibilities are taken from the analysis of satellite-derived albedo and CDNC by Quaas et al. (2008). For CDNC sensitivities to changes in AOD, standard deviations are derived from minimum and maximum values reported in the literature (Nakajima and Schulz, 2009; McComiskey and Feingold, 2012). Over ocean, maximum sensitivities are 0.927 in the $20-30^{\circ} \mathrm{S}$ belt (Kaufman et al., 2005b) and 0.771 elsewhere (Nakajima et al., 2001). Over land, maximum sensitivity is 0.471 (Myhre et al., 2007). Minimum sensitivities are 0.120 over ocean and 0.036 over land (Quaas et al., 2004). Using those minimum and maximum values to define a 4-sigma interval leads to the following standard deviations, used for all seasons: 0.16 over ocean, except in the $20-30^{\circ} \mathrm{S}$ oceanic belt where a value of 0.20 is used, and 0.11 over land. The 4-sigma interval covers a large range of sensitivities, effectively encompassing the difference between natural and present-day conditions, local and large-scale spatio-temporal variability, and most of the physically plausible range of 0 to 1. Albedo susceptibilities and CDNC sensitivities remain always positive, in accordance with the physics of the first indirect effect.

Table 5 lists the uncertain input distributions and parameters of the algorithm with their standard deviations. Cloud albedo susceptibilities are not shown, because they depend on modelled cloud cover and cloud optical depth through the use of three sets of regional and seasonal fitting parameters, as detailed in the Appendix of Quaas et al. (2008). The Monte-Carlo analysis does not include every sources of uncertainties. The prescribed vertical profile of anthropogenic 
Table 5. Summary of input distributions and parameters of the algorithm used in the MACC estimates of aerosol forcing. Standard deviations used to characterise probability density functions (PDFs) in the Monte-Carlo uncertainty analysis are also shown. PDFs are normal distributions, except for cases marked with (L), where a log-normal distribution is used. See Sect. 7 for details. AOD stands for aerosol optical depth, FMF for fine-mode fraction, and SSA for single-scattering albedo, all taken at $0.55 \mu \mathrm{m}$.

\begin{tabular}{lcc}
\hline Input distribution & Global noise & Gridbox-level noise \\
\hline Total AOD & \pm 0.030 & $\pm(0.03+0.05 \cdot$ AOD) (ocean) (L) \\
& & $\pm(0.05+0.15 \cdot$ AOD) (land) (L) \\
Mineral dust AOD & \pm 0.014 & $\pm(0.03+0.05 \cdot$ AOD) (ocean) (L) \\
& & $\pm(0.05+0.15 \cdot$ AOD) (land) (L) \\
Non-dust FMF & \pm 0.10 & $\pm 0.25(\mathrm{~L})$ \\
Cloud cover & \pm 0.03 & $\pm 0.10(\mathrm{~L})$ \\
\hline Parameter & Value and standard deviation \\
\hline Slope of marine AOD formula (Eq. 1) & $0.006 \pm 0.001$ \\
Offset of marine AOD formula (Eq. 1) & $0.060 \pm 0.005$ \\
Sea-salt and marine FMF (Eqs. 3 and 4$)$ & $0.30 \pm 0.20$ (L) \\
Threshold on FMF fcoarse & $0.35 \pm 0.05$ \\
Regional anthropogenic fractions & See Table 1 (L) \\
Regional SSAs & See Table 1 (L) \\
Cloud effective radius & $14 \pm 2.5 \mu \mathrm{m}$ \\
Cloud droplet number sensitivities & See Table 4 (L) \\
Cloud albedo susceptibilities & From Eq. (A6) in Quaas et al. (2008) (L) \\
\hline
\end{tabular}

and natural aerosols used in the radiative transfer calculations of DRE and DRF can cause errors in those estimates, as discussed in Sects. 4.1 and 4.2. Those errors are difficult to quantify in a Monte-Carlo framework. In addition, because the MODIS retrieval of total AOD, the ECMWF IFS, and the MACC aerosol RF distinguish different aerosol types, they assume aerosol optical properties that may not be consistent. However, all assumptions are based on AERONET retrievals and remain broadly similar. It is thus expected that the uncertainties introduced by such inconsistencies are small on a global average.

\section{Conclusions}

Estimation of aerosol forcing from the MACC aerosol re-analysis uses data-assimilated aerosol products from ECMWF in order to combine the strengths of satellitebased estimates, which are tied to actual aerosol distributions, with free-running model estimates, which do not include data gaps and may provide additional information. A Monte-Carlo analysis of uncertainties is used to translate PDFs of input distributions and parameters of the algorithm into PDFs of component AODs and radiative forcing. The globally-averaged anthropogenic AOD over the period $2003-2010$ is $0.073 \pm 0.013$. Uncertainties in total AOD and in the algorithm used to determine aerosol origin both contribute to make anthropogenic AOD uncertain. Clear-sky anthropogenic DRE is $-2.9 \pm 0.5 \mathrm{Wm}^{-2}$ at the TOA. Uncertainty is propagated from the anthropogenic AOD, and uncertain absorption properties also contribute. Clear-sky an- thropogenic DRF is $-2.5 \pm 0.5 \mathrm{Wm}^{-2}$ at the TOA. The best estimate of all-sky anthropogenic DRF is $-0.7 \mathrm{Wm}^{-2}$, or $-0.4 \mathrm{Wm}^{-2}$ if differences between present-day natural and pre-industrial aerosols are taken into account. The standard deviation for those estimates is $0.3 \mathrm{Wm}^{-2}$, but does not include the uncertainty in the pre-industrial aerosol distribution. Best estimate of all-sky IRF is $-0.6 \pm 0.4 \mathrm{Wm}^{-2}$, and its asymmetric PDF covers the range -0.1 to $-2 \mathrm{Wm}^{-2}$. Uncertainty in the CDNC sensitivity to anthropogenic changes in AOD dominates IRF uncertainty. Although uncertainty ranges derived in this study are similar to those obtained by the fourth IPCC assessment report (Forster et al., 2007), the best estimate of IRF is weaker.

The MACC aerosol products are not observations of aerosol radiative effects and forcings. The estimates are obtained by radiative transfer modelling and based on a number of simplifying assumptions. The anthropogenic AOD, for example, is in fact a size-based proxy for the actual anthropogenic AOD, which may never be derived from observations. However, the aerosol forcing products created as part of the MACC project represent a beneficial combination of the strengths of observationally-based and modelled-based estimates. Satellite estimates have the advantage of relying on observations, but for various reasons cannot offer a complete temporal and spatial coverage of the Earth's surface, thus introducing sampling biases in their statistics. Modelled estimates offer such a complete coverage, but can fail in simulating the complexity of real aerosol distributions. MACC aerosol forcing products are observationally-based within a model framework. 
The MACC aerosol reanalysis assimilates satellite aerosol retrievals to correct for model errors in simulating the total and fine-mode aerosol optical depths. The aerosol forcings are derived from those AODs and therefore benefit from the assimilation directly. Most other aerosol properties needed in the forcing estimates are also based on observations. For the direct forcing, size distributions and scattering and absorbing properties are taken from ground-based sun-photometer measurements. For the first indirect forcing, cloud susceptibilities to changes in aerosols are derived from satellite measurements.

In addition to providing another estimate of aerosol radiative effects and forcings, the MACC aerosol products have a variety of possible uses. First, they can provide corrections of surface fluxes for the radiative effects of natural and anthropogenic aerosols that typically decrease the downward shortwave flux reaching the surface. Scientists or engineers interested in the surface energy budget (e.g. hydrological cycle), vegetation and ecosystem services (e.g. carbon cycle) or solar energy can use the products to correct for changes in surface radiative fluxes due to the effect of aerosols. Second, MACC products can provide patterns of aerosol radiative forcing for detection and attribution studies using optimal finger printing techniques (see Appendix 9A of Hegerl et al., 2007). Although those techniques can correct for errors in the magnitude of anthropogenic and natural forcings, they require the knowledge of spatial and temporal patterns of specific forcing agents. Third, MACC products can provide initial conditions for seasonal and decadal forecasts, which require a good knowledge of the boundary conditions of the climate system. These include regional forcings due to shortlived species which can evolve during the forecast period. The MACC forcing products provide the aerosol contribution to such a forcing, and how that contribution has changed in the recent past, which is useful for hindcast simulations, and by extrapolation how it is likely to evolve in the near future. Fourth, MACC products can deliver trends in aerosol forcing. On a global scale, aerosol climate forcing is negative and offsets part of the positive forcing by greenhouse gases. A weaker aerosol forcing in the future would leave an increasing fraction of greenhouse gas forcing unopposed, exacerbating global warming (Andreae et al., 2000). The period of 2003-2010 currently covered by the MACC aerosol forcing products is too short to produce statistically significant trends, but it is expected that statistics will become increasingly robust as the MACC analysis progresses in the future. In any case, care is needed when looking at trends in the MACC products, especially at the global scale, because the satellite data which are assimilated in the aerosol monitoring system are known to have spurious trends due to calibration issues (Zhang and Reid, 2010). Finally, the MACC aerosol products can help in measuring the climate impacts of air quality policies. Air quality regulations aimed at improving human health have led to a strong decrease in anthropogenic emissions of aerosols and their precursors in Europe and
North America, followed by a decrease in particulate matter and an improvement in air quality. Emerging countries are likely to enact similar regulations in the future. A decrease in the concentration of most aerosol types translates into the removal of a cooling influence on climate, which can be assessed using MACC aerosol products.

Two planned improvements to the MACC aerosol data assimilation system are expected to bring important benefits to the estimation of aerosol forcing. First, the assimilation of MODIS aerosol fine-mode fractions will increase confidence in the anthropogenic AOD. Second, the assimilation of aerosol vertical profiles from the Cloud-Aerosol Lidar with Orthogonal Polarisation (CALIOP) satellite instrument will allow the estimation of aerosol direct effects in cloudy sky. In addition, land-based anthropogenic fractions, and regional datasets of single-scattering albedo of anthropogenic aerosols are currently prescribed over large regions (Table 1) with no account for seasonality. Those will be replaced by gridded datasets derived from an extended analysis of monthly sun-photometer measurements and AeroCom model simulations.

Daily distributions and monthly browses of aerosol radiative effects and forcing are freely available at www. gmes-atmosphere.eu/d/services/gac/reanalysis/forcing.

Products are currently available for the period 2003-2010, in netCDF format, and the database will be extended regularly as the MACC aerosol analysis progresses.

Acknowledgements. This work is funded by the Monitoring Atmospheric Composition and Climate (MACC) II project of the European Commission under the European Union Seventh Framework Programme, grant agreement number 283576, and supported by the Joint DECC/Defra Met Office Hadley Centre Climate Programme (GA01101).

Edited by: F. Yu

\section{References}

Abel, S.J., Haywood, J. M., Highwood, E. J., Li, J., and Buseck, P. R.: Evolution of biomass burning aerosol properties from an agricultural fire in southern Africa, Geophys. Res. Lett., 30, 1783, doi:10.1029/2003GL017342, 2003.

Anderson, T. L., Charlson, R. J., Bellouin, N., Boucher, O., Chin, M., Christopher, S. A., Haywood, J., Kaufman, Y. J., Kinne, S., Ogren, J. A., Remer, L. A., Takemura, T., Tanré, D., Torres, O., Trepte, C. R., Wielicki, B. A., Winker, D. A., and Yu, H.: An "ATrain" strategy for quantifying direct climate forcing by anthropogenic aerosols, B. Am. Meteorol. Soc., 12, 1795-1809, 2005.

Andreae, M. O.: Correlation between cloud condensation nuclei concentration and aerosol optical thickness in remote and polluted regions, Atmos. Chem. Phys., 9, 543-556, doi:10.5194/acp-9-543-2009, 2009.

Andreae, M. O., Jones, C. D., and Cox, P. M.: Strong present-day aerosol cooling implies a hot future, Nature, 435, 1187-1190, 2005. 
Bellouin, N., Boucher, O., Haywood, J., and Reddy, M. S.: Global estimate of aerosol direct radiative forcing from satellite measurements, Nature, 438, 1138-1141, 2005.

Bellouin, N., Jones, A., Haywood, J., and Christopher, S. A.: Updated estimate of aerosol direct radiative forcing from satellite observations and comparison against the Hadley Centre climate model, J. Geophys. Res., 113, D10205, doi:10.1029/2007JD009385, 2008.

Benedetti, A., Morcrette, J.-J., Boucher, O., Dethof, A., Engelen, R.J., Fisher, M., Flentje, H., Huneeus, N., Jones, L., Kaiser, J. W., Kinne, S., Mangold, A., Razinger, M., Simmons, A. J., and Suttie, M.: Aerosol analysis and forecast in the ECMWF integrated forecast system: 2. Data assimilation, J. Geophys. Res., 114, D13205, doi:10.1029/2008JD011115, 2009.

Bond, T. C., Doherty, S. J., Fahey, D. W., Forster, P.M., Berntsen, T., DeAngelo, B. J., Flanner, M. G., Ghan, S., Kärcher, B., Koch, D., Kinne, S., Kondo, Y., Quinn, P. K., Sarofim, M. C., Schultz, M. G., Schulz, M., Venkataraman, C., Zhang, H., Zhang, S., Bellouin, N., Guttikunda, S. K., Hopke, P. K., Jacobson, M. Z., Kaiser, J. W., Klimont, Z., Lohmann, U., Schwarz, J. P., Shindell, D., Storelvmo, T., Warren, S. G., and Zender, C. S.: Bounding the role of black carbon in the climate system: A scientific assessment, J. Geophys. Res., doi:10.1002/jgrd.50171, in press, 2013.

Christopher, S. A., Zhang, J., Kaufman, Y. J., and Remer, L. A.: Satellite-based assessment of top of atmosphere anthropogenic aerosol radiative forcing over cloud-free oceans, Geophys. Res. Lett., 33, L15816, doi:10.1029/2005GL025535, 2006.

Chung, C. E., Ramanathan, V., Kim, D., and Podgorny, I. A.: Global anthropogenic aerosol direct forcing derived from satellite and ground-based observations, J. Geophys. Res., 110, D24207, doi:10.1029/2005JD006356, 2005.

Cox, C. and Munk, W.: Statistics of the sea surface derived from sun glitter, J. Mar. Res., 13, 198-227, 1954.

de Graaf, M., Tilstra, L. G., Wang, P., and Stammes, P.: Retrieval of the aerosol direct radiative effect over clouds from spaceborne spectrometry, J. Geophys. Res., 117, D07207, doi:10.1029/2011JD017160, 2012.

Dubovik, O., Holben, B., Eck, T. F., Smirnov, A., Kaufman, Y. J., King, M. D., Tanré, D., and Slutsker, I.: Variability of absorption and optical properties of key aerosol types observed in worldwide locations, J. Atmos. Sci., 59, 590-608, 2002.

Forster, P., Ramaswamy, V., Artaxo, P., Berntsen, T., Betts, R., Fahey, D. W., Haywood, J., Lean, J., Lowe, D. C., Myhre, G., Nganga, J., Prinn, R., Raga, G., Schulz, M., and Van Dorland, R.: Changes in atmospheric constituents and in radiative forcing, in: Climate Change 2007: The Physical Science Basis, Contribution of Working Group I to the Fourth Assessment Report of the Intergovernmental Panel on Climate Change, edited by: Solomon, S., Qin, D., Manning, M., Chen, Z., Marquis, M., Averyt, K. B., Tignor, M., and Miller, H. L., Cambridge Univ. Press, New York, USA, 2007.

Grandey, B. S. and Stier, P.: A critical look at spatial scale choices in satellite-based aerosol indirect effect studies, Atmos. Chem. Phys., 10, 11459-11470, doi:10.5194/acp-10-11459-2010, 2010.

Hegerl, G. C., Zwiers, F. W., Braconnot, P., Gillett, N. P., Luo, Y., Marengo Orsini, J. A., Nicholls, N., Penner, J. E. and Stott, P. A.: Understanding and Attributing Climate Change, in: Climate Change 2007: The Physical Science Basis, Contribution of
Working Group I to the Fourth Assessment Report of the Intergovernmental Panel on Climate Change, edited by: Solomon, S., Qin, D., Manning, M., Chen, Z., Marquis, M., Averyt, K. B., Tignor, M., and Miller, H. L., Cambridge Univ. Press, New York, USA, 2007.

Kaufman, Y. J., Boucher, O., Tanré, D., Chin, M., Remer, L. A., and Takemura, T.: Aerosol anthropogenic component estimated from satellite data, Geophys. Res. Lett., 32, L17804, doi:10.1029/2005GL023125, 2005a.

Kaufman, Y. J., Koren, I., Remer, L. A., Rosenfeld, D., and Rudich, Y.: The effect of smoke, dust, and pollution aerosol on shallow cloud development over the Atlantic Ocean, P. Natl. Acad. Sci. USA, 102, 11207-11212, 2005b.

Key, J. R. and Schweiger, A. J.: Tools for atmospheric radiative transfer: STREAMER and FLUXNET, Comput. Geosci., 24, 443-451, 1998.

Kim, D., and Ramanathan V.: Solar radiation budget and radiative forcing due to aerosols and clouds, J. Geophys. Res., 113, D02203, doi:10.1029/2007JD008434, 2008.

Kinne, S., Schulz, M., Textor, C., Guibert, S., Balkanski, Y., Bauer, S. E., Berntsen, T., Berglen, T. F., Boucher, O., Chin, M., Collins, W., Dentener, F., Diehl, T., Easter, R., Feichter, J., Fillmore, D., Ghan, S., Ginoux, P., Gong, S., Grini, A., Hendricks, J., Herzog, M., Horowitz, L., Isaksen, I., Iversen, T., Kirkevåg, A., Kloster, S., Koch, D., Kristjansson, J. E., Krol, M., Lauer, A., Lamarque, J. F., Lesins, G., Liu, X., Lohmann, U., Montanaro, V., Myhre, G., Penner, J., Pitari, G., Reddy, S., Seland, O., Stier, P., Takemura, T., and Tie, X.: An AeroCom initial assessment - optical properties in aerosol component modules of global models, Atmos. Chem. Phys., 6, 1815-1834, doi:10.5194/acp-6-1815-2006, 2006.

Levy, R. C., Remer, L. A., Mattoo, S., Vermote, E. F., and Kaufman, Y. J.: Second-generation operational algorithm: Retrieval of aerosol properties over land from inversion of MODIS spectral reflectance. J. Geophys. Res., 112, D13211, doi:10.1029/2006JD007811, 2007.

Loeb, N. G., Kato, S., and Wielicki, B. A.: Defining top-of-theatmosphere flux reference level for Earth radiation budget experiments, J. Climate, 15, 3302-3309, 2002.

Lohmann, U., Quaas, J., Kinne, S., and Feichter, J.: Different approaches for constraining global climate models of the anthropogenic indirect aerosol effect, B. Am. Meteorol. Soc., 88, 243249, 2007.

Mangold, A., De Backer, H., De paepe, B., Ceburnis, D., Chiapello, I., Derimian, Y., Flentje, H., Huneeus, N., Kinne, S., Morcrette, J.-J., Benedetti, A., and Boucher, O.: Aerosol analysis and forecast in the ECMWF Integrated Forecast System, Part III: Evaluation by means of case studies, J. Geophys. Res., 116, D03302, doi:10.1029/2010JD014864, 2011.

McComiskey, A. and Feingold, G.: The scale problem in quantifying aerosol indirect effects, Atmos. Chem. Phys., 12, 1031-1049, doi:10.5194/acp-12-1031-2012, 2012.

McComiskey, A., Feingold, G., Frisch, A. S., Turner, D., Miller, M., Chiu, J., Min, Q., and Ogren, J.: An assessment of aerosol-cloud interactions in marine stratus clouds based on surface remote sensing, J. Geophys. Res., 114, D09203, doi:10.1029/2008JD011006, 2009.

Minnis, P., Young, D. F., Sun-Mack, S., Heck, P. W., Doelling, D. R., and Trepte, Q. Z.: CERES cloud property 
retrievals from imagers on TRMM, Terra, and Aqua, in: Proc. SPIE 10th International Symposium on Remote Sensing: Conference on Remote Sensing of Clouds and the Atmosphere VII, vol. 5235, Barcelona, Spain, 37-48, 2003.

Minnis, P., Sun-Mack, S., Chen, Y., Khaiyer, M. M., Yi Y., Ayers, J. K., Brown, R. R., Dong, X., Gibson, S. C., Heck, P. W., Lin, B., Nordeen, M. L., Nguyen, L., Palikonda, R., Smith, W. L., Spangenberg, D. A., Trepte, Q. Z., Xi, B.: CERES Edition-2 cloud property retrievals using TRMM VIRS and Terra and Aqua MODIS Data - Part II: Examples of average results and comparisons with other data, IEEE Trans. Geosci. Remote Sens., 49, 11, 4401-4430, doi:10.1109/TGRS.2011.2144602, 2011.

Morcrette, J.-J., Boucher, O., Jones, L., Salmond, D., Bechtold, P., Beljaars, A., Benedetti, A., Bonet, A., Kaiser, J. W., Razinger, M., Schulz, M., Serrar, S., Simmons, A. J., Sofiev, M., Suttie, M., Tompkins, A. M., and Untch, A.: Aerosol analysis and forecast in the ECMWF integrated forecast system: forward modeling, J. Geophys. Res., 114, D06206, doi:10.1029/2008JD011235, 2009.

Myhre, G.: Consistency between satellite-derived and modeled estimates of the direct aerosol effect, Science, 325, 187-190, 2009.

Myhre, G., Stordal, F., Johnsrud, M., Kaufman, Y. J., Rosenfeld, D., Storelvmo, T., Kristjansson, J. E., Berntsen, T. K., Myhre, A., and Isaksen, I. S. A.: Aerosol-cloud interaction inferred from MODIS satellite data and global aerosol models, Atmos. Chem. Phys., 7, 3081-3101, doi:10.5194/acp-7-3081-2007, 2007.

Nakajima, T. and Schulz, M.: What do we know about large-scale changes of aerosols, clouds, and the radiation budget?, in: Clouds and the Perturbed Climate System, Ernst Strüngmann Forum, edited by: Heintzenberg, J. and Charlson, R. J., ISBN 978-0-26201287-4, MIT Press, Cambridge, 2009.

Nakajima, T., Higurashi, A., Kawamoto, K., and Penner, J. E.: A possible correlation between satellite-derived cloud and aerosol microphysical parameters, Geophys. Res. Lett., 28, 1171-1174, 2001.

Penner, J. E., Xu, L., and Wang, M.: Satellite methods underestimate indirect climate forcing by aerosols, P. Natl. Acad. Sci. USA, 108, 13404-13408, doi:10.1073/pnas.1018526108, 2011.

Quaas, J., Boucher, O., and Bréon, F.-M.: Aerosol indirect effects in POLDER satellite data and in the LMDZ GCM, J. Geophys. Res., 106, 31991-32004, 2004.

Quaas, J., Boucher, O., and Lohmann, U.: Constraining the total aerosol indirect effect in the LMDZ and ECHAM4 GCMs using MODIS satellite data, Atmos. Chem. Phys., 6, 947-955, doi:10.5194/acp-6-947-2006, 2006.

Quaas, J., Boucher, O., Bellouin, N., and Kinne, S.: Satellite-based estimate of the direct and indirect aerosol climate forcing, J. Geophys. Res., 113, D05204, doi:10.1029/2007JD008962, 2008.

Quaas, J., Ming, Y., Menon, S., Takemura, T., Wang, M., Penner, J. E., Gettelman, A., Lohmann, U., Bellouin, N., Boucher, O., Sayer, A. M., Thomas, G. E., McComiskey, A., Feingold, G., Hoose, C., Kristjánsson, J. E., Liu, X., Balkanski, Y., Donner, L. J., Ginoux, P. A., Stier, P., Grandey, B., Feichter, J., Sednev, I., Bauer, S. E., Koch, D., Grainger, R. G., Kirkevåg, A., Iversen, T., Seland, Ø., Easter, R., Ghan, S. J., Rasch, P. J., Morrison, H., Lamarque, J.-F., Iacono, M. J., Kinne, S., and Schulz, M.: Aerosol indirect effects - general circulation model intercomparison and evaluation with satellite data, Atmos. Chem. Phys., 9, 8697-8717, doi:10.5194/acp-9-
8697-2009, 2009.

Quaas, J., Boucher, O., Bellouin, N., and Kinne, S.: Which of satellite- or model-based estimates is closer to reality for aerosol indirect forcing? - Reply to Penner, J. E., Xu, L., and Wang, M., P. Natl. Acad. Sci. USA, 108, E1099-E1099, doi:10.1073/pnas.1114634108, 2011.

Remer, L. A., Kaufman, Y. J., Mattoo, S., Martins, J. V., Ichoku, C., Levy, R. C., Kleidman, R. G., Tanré, D., Chu, D. A., Li, R. R., Eck, T. F., Vermote, E., and Holben, B. N.: The MODIS algorithm, products and validation, J. Atmos. Sci., 62, 947-973, doi:10.1175/JAS3385.1, 2005.

Schulz, M., Textor, C., Kinne, S., Balkanski, Y., Bauer, S., Berntsen, T., Berglen, T., Boucher, O., Dentener, F., Guibert, S., Isaksen, I. S. A., Iversen, T., Koch, D., Kirkevåg, A., Liu, X., Montanaro, V., Myhre, G., Penner, J. E., Pitari, G., Reddy, S., Seland, Ø., Stier, P., and Takemura, T.: Radiative forcing by aerosols as derived from the AeroCom present-day and pre-industrial simulations, Atmos. Chem. Phys., 6, 5225-5246, doi:10.5194/acp-6-5225-2006, 2006.

Smirnov, A., Holben, B. N., Eck, T. F., Dubovik, O., and Slutsker, I.: Effect of wind speed on columnar aerosol optical properties at Midway Island, J. Geophys. Res., 108, 4802, doi:10.1029/2003JD003879, 2003.

Stevens, B. and Feingold, G.: Untangling aerosol effects on clouds and precipitation in a buffered system, Nature, 461, 607-613, doi:10.1038/nature08281, 2009.

Stubenrauch, C. J., Rossow, W. B., Kinne, S., Ackerman, S., Cesana, G., Chepfer, H., Di Girolamo, L., Getzewich, B., Guignard, A., Heidinger, A., Maddux, B., Menzel, P., Minnis, P., Pearl, C., Platnick, S., Poulsen, C., Riedi, J., Sun-Mack, S., Walther, A., Winker, D., Zeng, S., Zhao, G.: Assessment of global cloud datasets from satellites: Project and database initiated by the GEWEX Radiation Panel, Bull. Amer. Meteor. Soc., in press, (2012).

Wielicki, B. A., Barkstrom, B. R., Harrison, E. F., Lee, R. B., Smith, G. L., and Cooper, J. E.: Clouds and the Earth's Radiant Energy System (CERES): an Earth observing system experiment, B. Am. Meteorl. Soc., 77, 853-868, 1996.

Yu, H., Dickinson, R. E., Chin, M., Kaufman, Y. J., Zhou, M., Zhou, L., Tian, Y., Dubovik, O., and Holben, B. N.: Direct radiative effect of aerosols as determined from a combination of MODIS retrievals and GOCART simulations, J. Geophys. Res., 109, D03206, doi:10.1029/2003JD003914, 2004.

Yu, H., Kaufman, Y. J., Chin, M., Feingold, G., Remer, L. A., Anderson, T. L., Balkanski, Y., Bellouin, N., Boucher, O., Christopher, S., DeCola, P., Kahn, R., Koch, D., Loeb, N., Reddy, M. S., Schulz, M., Takemura, T., and Zhou, M.: A review of measurement-based assessments of the aerosol direct radiative effect and forcing, Atmos. Chem. Phys., 6, 613-666, doi:10.5194/acp-6-613-2006, 2006.

Yu, H., Chin, M., Remer, L. A., Kleidman, R. G., Bellouin, N., Bian, H. and Diehl, T.: Variability of marine aerosol fine-mode fraction and estimates of anthropogenic aerosol component over cloud-free oceans from MODIS. J. Geophys. Res., 114, D10206, doi:10.1029/2008JD010648, 2009.

Wang, M., Ghan, S., Liu, X., L'Ecuyer, T. S., Zhang, K., Morrison, H., Ovchinnikov, M., Easter, R., Marchand, R., Chand, D., Qian, Y., Penner, J.E.: Constraining cloud lifetime effects of aerosols using A-Train satellite observations, Geophys. Res. 
Lett., 39, L15709, doi:10.1029/2012GL052204, 2012.

Zhang, J. and Reid, J. S.: A decadal regional and global trend analysis of the aerosol optical depth using a data-assimilation grade over-water MODIS and Level 2 MISR aerosol products, Atmos. Chem. Phys., 10, 10949-10963, doi:10.5194/acp-1010949-2010, 2010. 